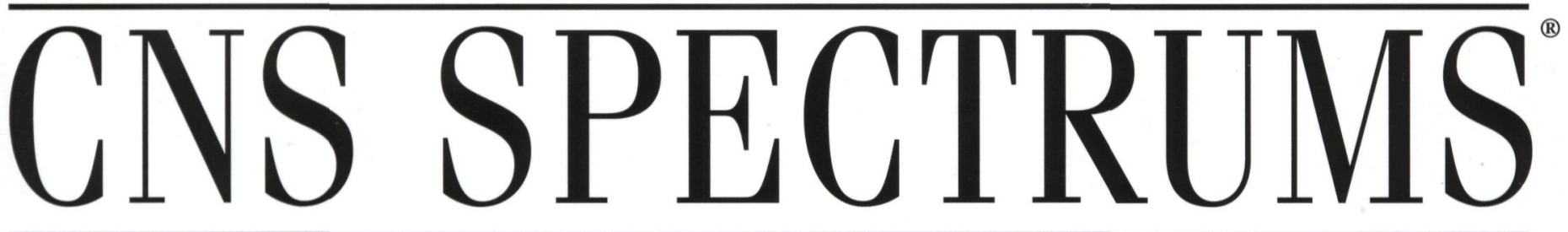

The International Journal of Neuropsychiatric Medicine

\title{
5
}

\section{HIV and the}

Central Nervous System

Part Two

Theory-Driven Interventions in Psychoneuroimmunology and HIV-1 Infection

M. D. Tyll, K. Goodkin, N. T. Blaney, T. T. Balderwicz, J. D. Hunt, and D. Asthana

Cognitive Effects of HIV-1 Infection

F. L. Wilkie, K. Goodkin, M. H. van Zuilen, M. D. Tyll, R. Lecusay, and T. Edrwin

HIV-1 Infection, Neuroendocrine Abnormalties, and Clinical Outcomes

M. Kumar, K. Goodkin, A. M. Kumar, T. T. Balderwicz, R. Morgan, and C. Eisdorfer

HIV-1-Associated Neuropathies

A. Verma and W. G. Bradley 


\section{In mild to moderate Alzheimer's disease}

\section{You see it as maintaining cognitive}

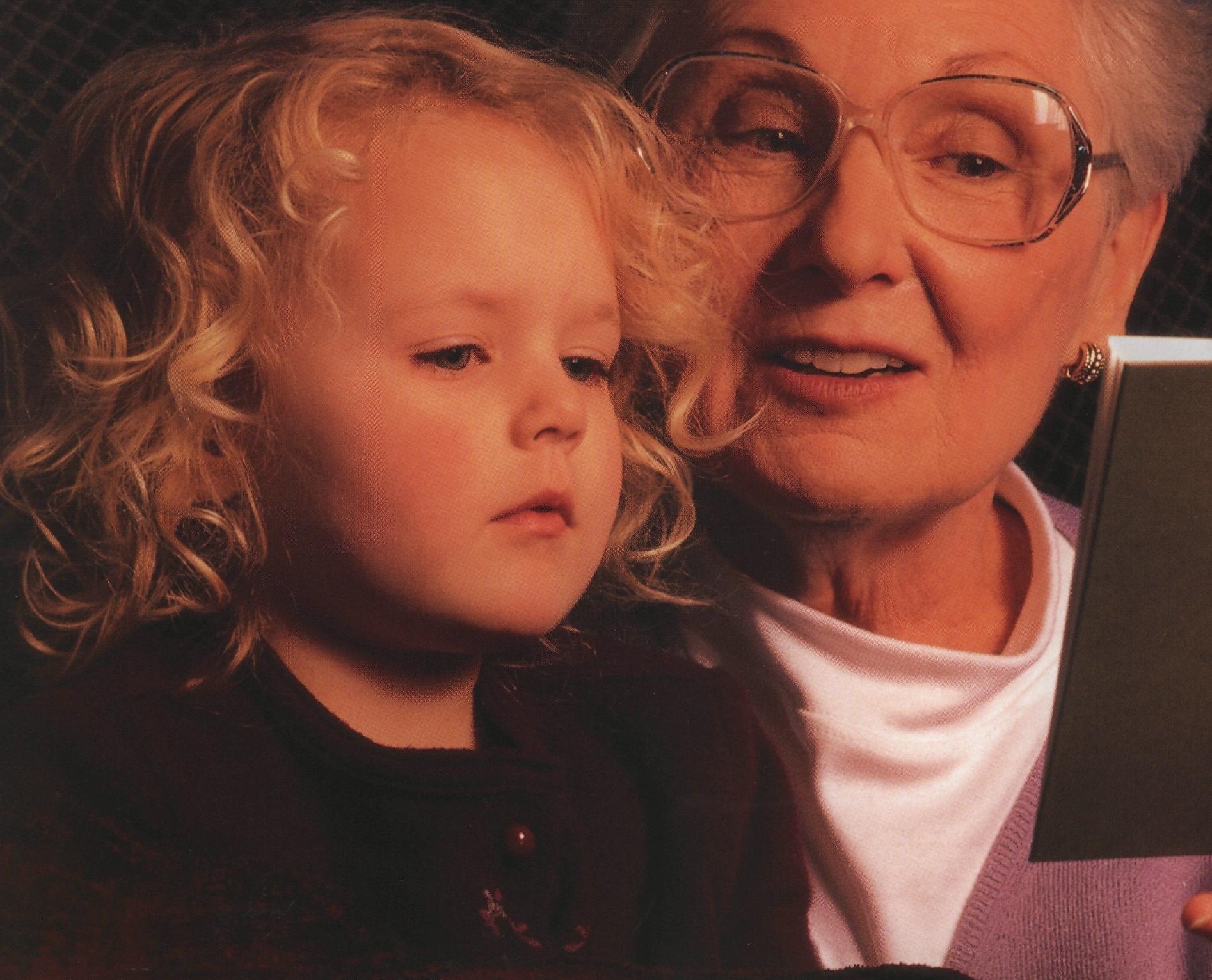

* Individual responses to ARICEPT ${ }^{\oplus}$ may include improvement, stabilization, or decline.

$\dagger$ The most common adverse events leading to discontinuation in pivotal clinical trials with $\mathrm{ARICEPT}^{\circledR}$ (donepezil $\mathrm{HCl}$ ) were nausea, diarrhea, and vomiting. Pivotal clinical trials of ARICEPT ${ }^{\circledR}$ have shown no increase, relative to placebo, in the incidence of either peptic ulcer disease or gastrointestinal bleeding. Nevertheless, cholinesterase inhibitors may be expected to increase gastric acid secretion. Therefore, patients (especially those at increased risk for developing ulcers - eg, having a history of ulcer disease, receiving concurrent nonsteroidal anti-inflammatory drugs) should be monitored closely for gastrointestinal bleeding. In pivotal clinical trials, syncopal episodes have been reported in association with ARICEPT $^{\oplus}$ ( $2 \%$ vs $1 \%$ for placebo). 


\section{function.}

She sees it as

a bedtime story.

ARICEPT ${ }^{\circledast}$. Helping to make

a difference for people living

with Alzheimer's

- Slows the worsening of symptoms*

- Proven to maintain cognition in placebo-controlled studies

- Well tolerated ${ }^{\dagger}$

- Proven safety profile

- Once-daily dosing

- 3 years of real-world use

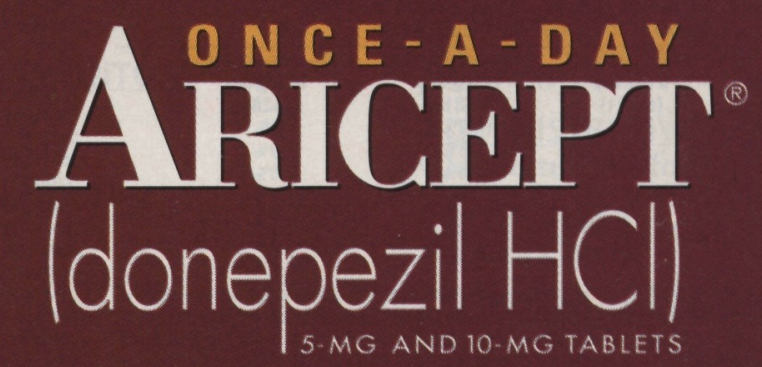

Therapy TO REMEMBER" 
ARICEPT (Donepezll Hydrochloride Tablets)

Brief Summary - see package insert for full prescribing intormation. INDICATIONS AND USAGE ARICEPT' is indicated for the treatment of mild to moderate dementia of the Alzheimer's type. CONTRAINDICATIONS ARICEPT is contraindicated in patients with known hypersensitivity to donepezil hydrochloride or to piperidine derivatives. WARNINGS Anesthesla: ARICEPT, as a cholinesterase inhibitor, is likely to exaggerate suecinylcholine-type muscle relaxation during anesthesia. Cardiovascular Condillons: Because of their pharmacological action, cholinesterase inhibitors may have vagotonic effects on heart rate (e.g. bradycardia). The potential for this action may be particularly important to patients with "sick sinus syndrome" or other supraventricular cardiac conduction conditions. Syncopal episodes have been reported in association with the use of ARICEPT' Gastrolntestinal Condifions: Through their primary action, cholinesterase inhibitors may be expected to increase gastric acid secretion due to increased cholinergic activity. Therefore, patients should be monitored closely for symptoms of active or occult gastrointestinal bleeding, especially those at increased fisk for developing ulcers, e.g. those with a history of ulcer disease or those receiving concurrent nonsteroidal anti-inflammatory drugs (NSAIDS). Clinical studies of ARICEPT thave shown no increase, relative to placebo, in the incidence of either reptic ulcer disease or gastrointestinal bleeding. ARICEPT ${ }^{*}$, as a predictable consequence of its pharmacological properties, has been shown to produce diarrhea, nausea and vomiting. These effects, when they occur, appear more frequently with the $10 \mathrm{mg} / \mathrm{day}$ dose than with the $5 \mathrm{mg} /$ day dose. In most cases, these effects have been mild and transient, sometimes lasting one to three weeks, and have resolved during continued use of ARICEPT ${ }^{\circ}$. Genflourinary: Although not observed in clinical trials of ARICEPT', cholinomimetics may cause bladder oufflow obstruction. Nourological Condtions: Seizures: Cholinomimetics are believed to have some potential to cause generalized convulsions. However, seizure activity also may be a manitestation of A lzheimer's Disease. Pu/monary Condftlons: Because of their cholinomimetic actions, cholinesterase inhibitors should be prescribed with care to patients with a history of asthma or obstructive pulmonary disease. PRECAUTIONS Drug-Drug Interactions Drugs Highly Bound to Plasma Protoins: Drug displacement studies have been performed in vitro between this highly bound drug $(96 \%)$ and other drugs such as furosemide, digoxin, and warlarin. ARICEPT at concentrations of $0.3-10 \mu \mathrm{g} / \mathrm{mL}$ did not affect the binding of furosemide $(5 \mu \mathrm{g} / \mathrm{mL})$, digoxin $(2 \mathrm{ng} / \mathrm{mL})$, and warfarin $(3 \mu \mathrm{g} / \mathrm{mL})$ to human alburmin. Similarly, the binding of ARICEPT to human albumin was not affected by furosemide, digoxin, and warfarin. Effact of ARICEPT on the Metabolism of Other Drugs: $N$ No in vivo clinical trials have investigated the effect of ARICEPT" on the clearance of drugs metabolized by CYP $3 A 4$ (e.g. cisapride, terienadine) or by CYP 2D6 (e.g. imipramine). However, in vitro studies show a low rate of binding to these enzymes (mean $K_{i}$ about 50-130 $\mu \mathrm{M}$ ), that, given the therapeutic plasma concentrations of donepezil (164 nM), indicates little likelihood of interterence. Whether ARICEPT has any potential for enzyme induction is not known. Effect of Other Drugs on the Metabolism of ARICEPT: Ketoconazole and quinidine, inhibitors of CYP450, $3 A 4$ and 206 , respectively, inhibit donepezil metabol ism in vitro. Whether there is a clinical effect of these inhibitors is not known. inducers of CYP 206 and CYF $3 A 4$ (e.g. phenytoin, carbamazepine, dexamethasone, ritampin, and phenobarbital) could increase the rate of elimination of ARICEPT?. Use with Anticholinergics: Because of their mechanism of action cholinesterase inhibitors have the potential to interfere with the activity of anticholinergic medications. Use with Cholinomimetlos and Other Cholinestorase inhibitors: A synergistic effect may be expected when cholinesterase intibitors are given concurrently with succinylcholine, similar neuromuscular blocking agents or cholinergic agonists such as bethanechol. Carclnogenesis, Mutagenesis, Impairment of Fertllity Carcinogenicity studies of donepezil have not been completed. Donepezil was not mutagenic in the Ames reverse mutation assay in bacteria. In the chromosome aberration test in cultures of Chinese hanster lung $(\mathrm{CHL})$ cells, some clastogenic effects were observed. Donepezil was not clastogenic in the in vivo mouse micronucleus test. Donepezil had no effect on fertility in rats at doses up to $10 \mathrm{mg} / \mathrm{kg} /$ day (approximately 8 times the maximum: recommended human dose on a mg/m² basis). Pregnancy Pregnancy Category $C$ : Teratology studies conducted in pregnant rats at doses up to $16 \mathrm{mg} / \mathrm{kg} /$ day (approximately 13 times the maximum recommended human dose $0 \mathrm{~m}^{2} \mathrm{mgsis}$ ) and in pregnant rabbits

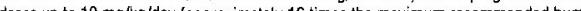
doses up dose on a donepezil. However, in a study in which pregnant rals were given up to $10 \mathrm{mg} / \mathrm{kg} / \mathrm{day}$ (approximately 8 times the maximum recommended human dose on a mg/m $\mathrm{m}^{2}$ basis)
from day 17 of gestation through day 20 postpartum, there was a stight increase in still births and a slight decrease in pup survival through day 4 postpartum at this dose: the next lower dose tested was $3 \mathrm{mg} / \mathrm{kg} / \mathrm{day}$. There are no adequate or well-controlled studies in pregnant women. ARICEPT should be used during pregnancy only if the potential benefit justifies the potential risk to the fetus. Mursing Mothers it is not known whether donepezil is excreted in human breast milk. ARICEPT ${ }^{\mathbb{s}}$ has no indication for use in nursing mothers. Pediatric Use There are no adequate and well-controlled trials to document the safety and efficacy of ARICEPT in any illness occurring in children. ADVERSE REACTIONS Adverse Events Leading to Discontinuation The rates of discontinuation from controlled clinical trials of ARICEPT due to adverse events for the ARICEPT 5 mg/day treatment grouss were comparable to those of place of discontinution of patients who rocerved 7 -day ascalations from 5 molday to 10 molday was higher at $13 \%$. The most in incidence seen in placebo patients, are shown in Tabie 1.

Table 1. Most Frequent Adverse Events Leading to Withdrawal from Controlled Cilnical Trials by Dose Group

\begin{tabular}{lccc}
\hline Dose Group & Placebo & $\mathbf{5 ~ m g / d a y ~ A R I C E P T ~}$ & $\mathbf{1 0}^{*} \mathbf{~ m g / d a y ~ A R I C E P T ~}$ \\
Patlents Randomized & 355 & 350 & 315 \\
Event\%Dlscontinuing & & & \\
Nausea & $1 \%$ & $1 \%$ & $3 \%$ \\
Diarthea & $0 \%$ & $<1 \%$ & $3 \%$ \\
Vomiting & $<1 \%$ & $<1 \%$ & $2 \%$
\end{tabular}

Most Frequent Adverse Clinical Events Seen In Association with the Use of ARICEPT- The most cominon adverse events, defined as those occurring at a frequency of at least $5 \%$ in patients receiving $10 \mathrm{mg} /$ day and twice the placebo rate, are largely predicted by ARICEPT 's cholinomimetic effects. These include nausea, diarthea, insomnia, vomiting, muscle cramp, fatigue and anorexia. These adverse events were often of mild intensity and transient, resolving during continued ARICEPT treatment without the need for dose modification. There is evidence to suggest that the frequency of these common adverse events may be affected by the rate of titration. An open-label study was conducted with 269 patients who received placebo in the 15- and 30-week studies. These patients were titrated to a dose of $10 \mathrm{mg} / \mathrm{day}$ over a 6 -week period. The rates of common adverse events were lower than those seen in patients titrated to $10 \mathrm{mg} /$ day over one week in the controlled clinical trials and were comparable to those seen in patients on $5 \mathrm{mg} / \mathrm{day}$. See Table 2 for a comparison of the mosi common adverse events following one and six week titration regimens.

Table 2. Comparison of Rates of Adverse Events in Patients Titrated to $10 \mathrm{mg} / \mathrm{day}$ Over 1 and 6 Weaks

\begin{tabular}{lcccc}
\hline Adverse Event & $\begin{array}{c}\text { Placebo } \\
(\mathbf{n = 3 1 5 )}\end{array}$ & $\begin{array}{c}\text { No titration } \\
\mathbf{5} \mathbf{~ m g / d a y} \\
\mathbf{( n = 3 1 1 )}\end{array}$ & $\begin{array}{c}\text { One-we日k tltratlon } \\
\mathbf{1 0} \mathbf{~ m g / d a y} \\
\mathbf{( n = 3 1 5 )}\end{array}$ & $\begin{array}{c}\text { Six-week titration } \\
\mathbf{1 0} \mathbf{~ m g} / \mathbf{d a y} \\
(\mathbf{n = 2 6 9 )}\end{array}$ \\
Nausea & $6 \%$ & $5 \%$ & $19 \%$ & $6 \%$ \\
Diarthea & $5 \%$ & $8 \%$ & $15 \%$ & $9 \%$ \\
Insomnia & $6 \%$ & $6 \%$ & $14 \%$ & $6 \%$ \\
Fatigue & $3 \%$ & $4 \%$ & $8 \%$ & $3 \%$ \\
Vomiting & $3 \%$ & $3 \%$ & $8 \%$ & $5 \%$ \\
Muscle cramps & $2 \%$ & $6 \%$ & $8 \%$ & $3 \%$ \\
Anorexia & $2 \%$ & $3 \%$ & $7 \%$ & $3 \%$
\end{tabular}

Adverse Events Reported in Controlled Trials The events cited retlect experience gained under closely monitored conditions of clinical triais in a highly selected patient population. In actual clinical practice or in other clinical trials, these frequency estimates may not apply, as the conditions of use, reporting behavior, and the kinds of patients treated may differ. Table 3 lists treatment emeroent signs and symptoms that were reported in at least $2 \%$ of patients in placebo-controlled trials who received ARICEPT and for which the rate of occurrence was greater for ARICEPT assigned than placebo assigned patients. In general, adverse events occurred more frequently in female patients and with advancing age.
Table 3. Adverse Events Reported in Controlled Clinical Trlals

in at Least $2 \%$ of Patlents Receiving ARICEPT (donepezIl HCI) and at a Higher Frequency than Placebo-treated Patients

\begin{tabular}{|c|c|c|}
\hline Body System/Adverse Event & $\begin{array}{l}\text { Placebo } \\
(n=355)\end{array}$ & $\begin{array}{c}\text { ARICEP) } \\
(n=747\end{array}$ \\
\hline \multicolumn{3}{|l|}{$\begin{array}{l}\text { Percent of Patlents with any Adverse Event } \\
\text { Body as a Whole }\end{array}$} \\
\hline Headache & 9 & 10 \\
\hline Pain, various locations & 8 & 9 \\
\hline Accident & 6 & 7 \\
\hline Fatigue & 3 & 5 \\
\hline \multicolumn{3}{|l|}{ Cardiovascular System } \\
\hline Syncope & 1 & 2 \\
\hline \multicolumn{3}{|l|}{ Dlgestive System } \\
\hline Nausea & 6 & 11 \\
\hline Diarrhea & 5 & 10 \\
\hline Vomiting & 3 & 5 \\
\hline Anorexia & 2 & 4 \\
\hline \multicolumn{3}{|l|}{ Hemic and Lymphatic System } \\
\hline Ecchymosis & 3 & 4 \\
\hline \multicolumn{3}{|l|}{ Metabollc and Nutritional Systems } \\
\hline Weight Decrease & 1 & 3 \\
\hline \multicolumn{3}{|l|}{ Musculoskeletal System } \\
\hline Muscle Cramps & 2 & 6 \\
\hline Arthritis & 1 & 2 \\
\hline \multicolumn{3}{|l|}{ Nervous System } \\
\hline Insomnia & 6 & 9 \\
\hline Dizziness & 6 & 8 \\
\hline Depression & $<1$ & 3 \\
\hline Abnormal Dreams & 0 & 3 \\
\hline Somnolence & $<1$ & 2 \\
\hline \multicolumn{3}{|l|}{ Urogenital System } \\
\hline Frequent Urination & 1 & 2 \\
\hline
\end{tabular}

Other Adverse Events Observed During Clinical Trlals ARICEPT has been administered to over 1700 individuals during clinical trials worldwide. Approximately 1200 of these patients have been treated for at least 3 months and more the 1000 patients have ween treated for at least 6 months. Controlled and uncontrolled trials in the United States included ap roximately 900 patients in regrds to the highest dose of 10 molday his population includes 650 patients treated for 3 months, 475 patients treated to Dox 475 patients treated tor 6 months and 116 patiants treated for over 1 year. The range of patient exposure is from 1 $\begin{array}{ll}\text { A - D A Y } & 101214 \text { days. Treatment emergent signs and symptoms that occurred during } \\ 3 \text { controlled clinical trials and two open-label trials in the United States were recorded as }\end{array}$ adverse events by the clinical investigators using terminology of their own choosing. To provide an overall estimate of the proportion of individuals having similar types of events, the events were grouped into a smal ler number of standardized categories using a modified COSTART dictionary and event frequencies were calculated across all studies. Thes categories are used in the listing below. The frequencies represent the proportion of 900 patients from these trials who experienced that event while receiving ARICEPT ${ }^{3}$. A adverse events occurring at least twice are included, except for those already listed in Tables 2 or 3, COSTART terms too general to be informative, or events less likely to be drug caused. Events are classified by body systemt and listed using the following definitions frequent adverse events - those occurring in at least $1 / 100$ patients: infrequent adverse frequent adverse events - those occurring in at least $1 / 100$ patients: infrequent advers events - those occurring in $1 / 100$ to $1 / 1000$ patients. These adverse events are not necNMEMIBER trequency in placebo-treated patients in the controlled studies. No important additional adverse events were seen in studies conducted outside the United States. Body as a Whole: Frequent: influenza, chest pain, toothache; Intrequent: fever conducted outside the United States. Body as a Whole: Frequent: influenza, chest pain, toothache; Infreguent: fever Cardiovascular System: Frequent: hypertension, vasod lation, atrial fibrillation, hot flashes, hypotension; Infrequen angina pectoris, posfural hypotension, myocardial infarction, AV block (first degree), congestive heart failure, arteritis, bradycardia, peripheral vascular disease, supraventricular tachycardia, deep vein thrombosis. Digestlve System: Frequent: fecal incontinence, gastrointestinal bleeding, bloating, epigastric pain; infrequent eructation, gingivitis, increase appetite, flatulence, periodontal abscess, cholelithiasis, diverticulitis, drooling, dry mouth, fever sore, gastritis, irritable colon, tongue edema, epigastric distress, gastroenteritis, increased transaminases, hemorrhoids, ileus, increased thirs, jaundice, melena, polydipsia, duodenal ulcer. stomach ulcer. Endocrine System: Intrequent: diabetes mellitus, goiter. Hemic and Lymphatic System: Infrequent: anemia, thrombocythemia, thrombocytopenia, eosinophilia,
enthrocytopenia. Metabolic and Mutritlonal Disorders: Frequent: dehydration; Infrequent gout, hypokalemia, increased creatine enythrocytopenia. Metabolic and Nutritlonal Disorders: Frequent: dehydration; Infrequent: gout, hypokalermia, increased crealin kinase, hyperglycemia, weight increase, increased lactate dehydrogenase. Musculoskeletai System: Frequent: bone fracture;
infrequent: muscle weakness, muscle fasciculation. Nervous System: Frequent: delusions, tremor, irritability, paresthesia, Infrequent: muscle weakness, muscle fasciculation. Nervous System: Frequent: delusions, tremor, irritability, paresthesia,
aggression, vertigo, ataxia, increased libido, restlessness, abnormal crying, nervousness, aphasia' infrequent: cerebrovascular aggression, vertigo, ataxia, increased libido, restlessness, abnormal crying, nervousness, aphasia', Infrequent: cerebrovascular
accident, intracranial hemorrhage, transient ischemic attack, emotional lability, neuralgia, coldness (localized). accident, intracranial hemorrhage, transient ischemic attack, emotional lability, neuralgia, coldness (localized)
muscle spasm, dysphoria, gait abnormality, hypertonia, hypokinesia, neurodermatitis, numbness (localized), paranoia dysarthria, dysphasia, hostility, decreased libido, melancholia, emotional withdrawal, nystagmus, pacing. Respiratory System: Frequent: dyspnea, sore throat, bronchitis; infrequent: epistaxis, post nasal drip, pneumonia, hyperventilation pulmonary congestion, wheezing, hypoxia, pharyngitis, pleurisy, pulmonary collapse, sleep apnea, snoring. Skin and Appondages: Frequent: pruritus, diaphoresis, urticaria; inirequent: dermatitis, erythema, skin discoloration hyperkeratosis, alopecia, fungal dermatitis, herpes zoster, hirsutism, skin striae, night sweats, skin ulcer. Special Senses: Frequent. calaract, eye irritation, vision blurred; Infrequent: dry eyes, glaucoma, earache, tinnitus, blepharitis, decreased hearing retinal hemorrhage, otitis externa, otitis media, bad taste, conjunctivat hemorrtiage, ear buzing, motion sickness, spots before eyes. Urogenlial System: Frequent: urinary incontinence, nocturia; infrequent: dysuria, hematuria, urinary urgency, metrorrhagia, cystitis, enuresis, prostate hypertrophy, pyelonephritis, inability to empty bladder, breast fibroadenosis fibrocystic breast, mastitis, pyuria, renal failure, vaginitis. Postintroduction Reports voluntary reports of adverse events temporally associated with ARICEPT that have been received since market introduction that are not listed above, and that there is inadequate data to determine the causal relationship with the drug include the following: abdominal pain, agitation, cholecystitis, confusion, convulsions, hallucinations, heart block (all types), hemolytic anemia, hepatitis, hyponatremia cholecystitis, confusion, convulsions, hallucinations, heart block (all types), hemolytic anemia, hepatitis, hyponatremia pancreatitis, and rash. Oble to contact a Poison Control Center to determine the latest recommendations to the management of an overdose of any drug. As in any case of overóose, general supportive measures should be utilized. Overdosage with cholinesterase inhibitors can result in cholinergic crisis characterized by severe nausea, vomiting salivation, sweating, bradycardia, hypotension, respiratory depression, collapse and convuisions. Increasing muscle weakness is a possibility and may result in death if respiratory muscles are involved. Tertiary anticholinergics such as atropine may be used as an antidote for ARICEPT overdosage. Intravenous atropine sulfate titrated to effect is recommended: an initial dose of 1.0 to $2.0 \mathrm{mg} \mathrm{IV}$ with subsequent doses based upon clinical response. Alypical responses in blood pressure and heart rate have been reported with other cholinomimetics when co-administered with quaternary anticholinergics such as giycopyrrolate. It is not known whether ARICEPT ${ }^{\oplus}$ and/or its metabolites can be removed by dialysis (hemodialysis, peritoneal dialysis, of hemofiltration). Dose-related signs of toxicity in animals included reduced spontaneous movement, prone position staggering gait, lacrimation, clonic convulsions, depressed respiration, salivation miosis, tremors, fasciculation and lower body suriace temperature. DOSAGE AND ADMINISTRATION The dosages of ARICEPT ${ }^{\circ}$ shown 10 be effective in controlled clinical trials are $5 \mathrm{mg}$ and $10 \mathrm{mg}$ administered once per day. Controlled clinical trials indicated that the $10 \mathrm{mg}$ dose, with a one week titration, is likely to be associated with a higher incidence of cholinergic adverse events than the 5 $\mathrm{mg}$ dose. Because steady state is not achieved for 15 days and because the incidence of such effects may be influenced by the rate of dose escalation, treatment with a dose of $10 \mathrm{mg}$ should not be contemplated until patients have been on a daily dose of $5 \mathrm{mg}$ for 4 to 6 weeks. Whether or not to employ a dose of $10 \mathrm{mg}$ is a matter of prescriber and patient preference. ARICEPT should be taken in the evening, just prior to retiring, and may be taken with or without food. 


\section{CNS SPECTRUMS}

The International Journal of Neuropsychiatric Medicine

\section{EDITOR}

Eric Hollander, MD

Mount Sinai School of Medicine New York, NY

\section{INTERNATIONAL EDITOR}

Joseph Zohar, MD

Chaim Sheba Medical Center

Tel Aviv, Israel

\section{ASSOCIATE INTERNATIONAL EDITOR \\ Donatella Marazziti, MD \\ University of Pisa \\ Pisa, Italy}

\section{EDITORIAL DIRECTOR}

James La Rossa Jr.

\section{BOARD OF ADVISORS}

Margaret Altemus, MD

Cornell University Medical Center New York, NY

Mitchell F. Brin, MD

Mount Sinai School of Medicine

New York, NY

John Caronna, MD

New York Hospital-Cornell

Medical Center, New York, NY

Dennis S. Charney, MD

Yale University

New Haven, CT

Emil F. Coccaro, MD

University of Chicago Medical Center

Chicago, IL

Jeffrey L. Cummings, MD

University of California

Los Angeles, CA
Dwight L. Evans, MD

University of Pennsylvania

Philadelphia, PA

Mark George, MD

Medical University of South Carolina

Charleston, SC

Jack Gorman, MD

College of Physicians and

Surgeons, Columbia University

New York, NY

Thomas R. Insel, MD

Yerkes Primate Labs

Emory University School of Medicine Atlanta, GA

Lorrin M. Koran, MD

Stanford University Medical School Stanford, CA

Herbert Y. Meltzer, MD

Vanderbilt University Medical Center Nashville, TN

Stuart A. Montgomery, MD

St. Mary's Hospital Medical School

London, United Kingdom

Dennis L. Murphy, MD

National Institute of Mental Health Bethesda, MD

Charles B. Nemeroff, MD, PhD Emory University School of Medicine Atlanta, GA

Humberto Nicolini, MD, PhD

Instituto Mexicano de Psiquiatria Mexico

Katharine Phillips, MD

Brown University

Providence, RI
Harold A. Pincus, MD

American Psychiatric Association

Washington, DC

Stanley I. Rapoport, MD

National Institute of Mental Health Bethesda, MD

Scott L. Rauch, MD

Massachusetts General Hospital

Charlestown, MA

Alan Schatzberg, MD

Stanford University Medical School

Stanford, CA

Dan J. Stein, MB

University of Stellenbosch

Tygerberg, South Africa

Norman Sussman, MD

New York University Medical School New York, NY

Neal R. Swerdlow, MD, PhD

University of California, San Diego

La Jolla, CA

Michael R. Trimble, MD

National Hospital for Neurology

and Neurosurgery

London, United Kingdom

H. M.van Praag, MD

University of Maastricht

Maastricht, The Netherlands

Herman G.M. Westenberg, MD

University Hospital Utrecht

Utrecht, The Netherlands

Richard Wyatt, MD

National Institute of Mental Health

Bethesda, MD

Stuart Yudofsky, MD

Baylor College of Medicine

Houston, TX

\section{MBL COMMUNICATIONS}

\section{CEO \& PUBLISHER}

James La Rossa Jr.

PRESIDENT \&

ASSOCIATE PUBLISHER

Darren L. Brodeur

MANAGING EDITOR

Claire R. Roberts

ASSOCIATE EDITORIAL DIRECTOR/

ACQUISITIONS EDITOR

Genevieve Romano

SENIOR EDITOR

Jenny R. Green

SPECIAL PROJECTS EDITOR

Imre Balanli

PUBLISHING ASSOCIATE

Jesse D. Soll
NATIONAL ACCOUNTS

MANAGER-

EMERGING MARKETS

Paul McDaniel

ASSISTANT

ACQUISITIONS EDITORS

Kathleen Byrne

Dena Panteleakis

EDITORIAL ASSISTANTS

Jill Bazar

Janeen Labbe

Keith Papa

Craig McRea Seip

Joshua Ubaldi

Jessica Wapner

ART DIRECTOR

Anthony J. Korsak

\section{ASSISTANT ART DIRECTOR}

Benjamin Balcomb

COPY EDITORS

Lauren Cerruto

Michelle Cervone, MD

John Martino

ADMINISTRATIVE ASSISTANT

Claudette Crawford

CONTROLLER

Richard Cortez

CORPORATION COUNSEL

Kevin F. Saer, Esq.

Davis, Wright, \& Tremaine, LLP

\section{OF COUNSEL}

Susan G. La Rossa, Esq.

Putney, Twombly, Hali \& Hirson 
ADDING TO THE THERAPEUTIC ARMAMENTARIUM

\section{page 25}

"Controlling for baseline antiretroviral medication use, prophylaxis against lethal complications, CD4 cell count, viral load, and CDC clinical disease stage, the authors observed a significant effect on the number of copies of plasma HIV-1 RNA in the seropositive participants. The relative mean change before and after intervention was $0.78 \log _{10}$, which is greater than the minimum change required to establish the efficacy of an antiretroviral medication. Finally, a significant reduction in the number of health care visits over 6 months was achieved both in the seronegative and seropositive groups, demonstrating that these immunologic changes may be clinically relevant. Based on these findings, it may be suggested that a bereavement support-group intervention can offer psychological benefits that yield a positive neuroendocrine effect on plasma cortisol levels. This effect in turn has a positive immunologic effect on CD4 cell count, NK cells, and the lymphocyte proliferative response to $\mathrm{PHA}$, resulting in a decreased viral load and increased clinical health benefits."

\section{COGNITIVE IMPAIRMENT: A PREVALENT PROBLEM IN HIV-1 INFECTION \\ page 33}

"The nature of the memory impairment observed in HIV1 infection resembles that seen in Huntington's disease, a subcortical brain disease with a pattern of memory impairment different from that of cortical dementias, such as Alzheimer disease. Specifically, individuals with either subcortical or cortical brain disease have difficulty during the acquisition and recall of verbal information. Differences between individuals with subcortical and individuals with cortical brain disease, however, are observed in cued recall and especially in recognition memory. Individuals with HIV-1 infection as well as those with Huntington's disease are significantly aided by a cued or recognition format, suggesting that their impairment is primarily one of retrieval of information from memory. In contrast, patients with Alzheimer disease perform just as poorly with a cued or recognition test format as with free recall, suggesting that their memory deficits extend to encoding and storage of information. The subcortical type of verbal memory impairment described above is more likely to occur in individuals with AIDS than in those at earlier stages of the infection. Of interest was the finding that patients with Huntington's disease had impaired performance on a Rotary Pursuit learning task, while those with HIV-1 infection were able to perform as well as the normal control group on this task, which includes a motor component. Therefore, the similarity between Huntington's disease and HIV-1 infection may be in the nature of the memory impairment and not in the decrements in motor skills associated with the distinctive motor changes characterizing these two diseases."

\section{A LEADING ROLE IN THE CLINICAL PROGRESSION OF THE DISEASE PROCESS? page 55}

"The etiology and pathogenesis of HIV-l infection is complicated. Immediately after contracting HIV-1 infection, although patients remain seronegative for a variable time period, viral infection may induce intense internal physiological distress characterized by possibly heightened cortisol levels. Unfortunately, systematic studies during the window period from viral exposure to seroconversion are of limited feasibility, since most individuals are typically not aware of viral exposure or that a flu-like syndrome they may have experienced is referable to acute HIV-1 infection. Nevertheless, early studies showed a significant increase in levels of cortisol in recently diagnosed subjects and in the bereaved. It is very likely that a higher cortisol concentration immediately after contracting HIV-1 infection and in response to bereavement is the result of heightened levels of $\mathrm{CRH}$. Chronically, as described above, this phenomenon will down-regulate the $\mathrm{CRH}$ receptors and decrease the sensitivity of the corticotrophs, leading to attenuated ACTH and cortisol responses. Recent experimental studies have investigated central HPA activity under conditions of acute and chronic stressor exposure. It has been observed in acute stressor exposure that $\mathrm{CRH}$ is mainly responsible for stimulating the activity of ACTH. In contrast, with chronic or repeated stressor exposure, arginine vasopressin (AVP) is the main secretogogue. Since parvicellular neurons that secrete only AVP, in contrast to those that secrete both CRH and AVP, are devoid of glucocorticoid receptors, AVP production is relatively independent of the cortisol-mediated negative feedback system."

\section{PERIPHERAL NERVE INVOLVEMENT: TAILORED NEUROPATHIES page 66}

"Although direct HIV-1 infection may not be the principal pathogenetic mechanism, DSP occurs invariably in a setting of chronic productive HIV-1 infection and progressive immunodeficiency with or without opportunistic infections. It is, therefore, possible that DSP is virus driven-perhaps resulting from some indirect mechanism(s) in HIV-1 infection. Recent research has focused on the action of cytokines on the PNS in AIDS patients. Tumor necrosis factor- $\alpha$, several interleukins, transforming growth factor- $\alpha$, and nitric oxide have all been identified in the peripheral nerves or in the dorsal root ganglia of HIV-1-infected patients. The glycoprotein 120 subunit of HIV-1 may be a cofactor. In addition, certain HIV-1 strains, host factors, and cytokine interaction with nerve growth factors have also been speculated in DSP pathogenesis. Finally, the contributory role, if any, of concurrent CMV infection, malnutrition, and/or AIDS wasting in the etiology of DSP is tantalizing." 


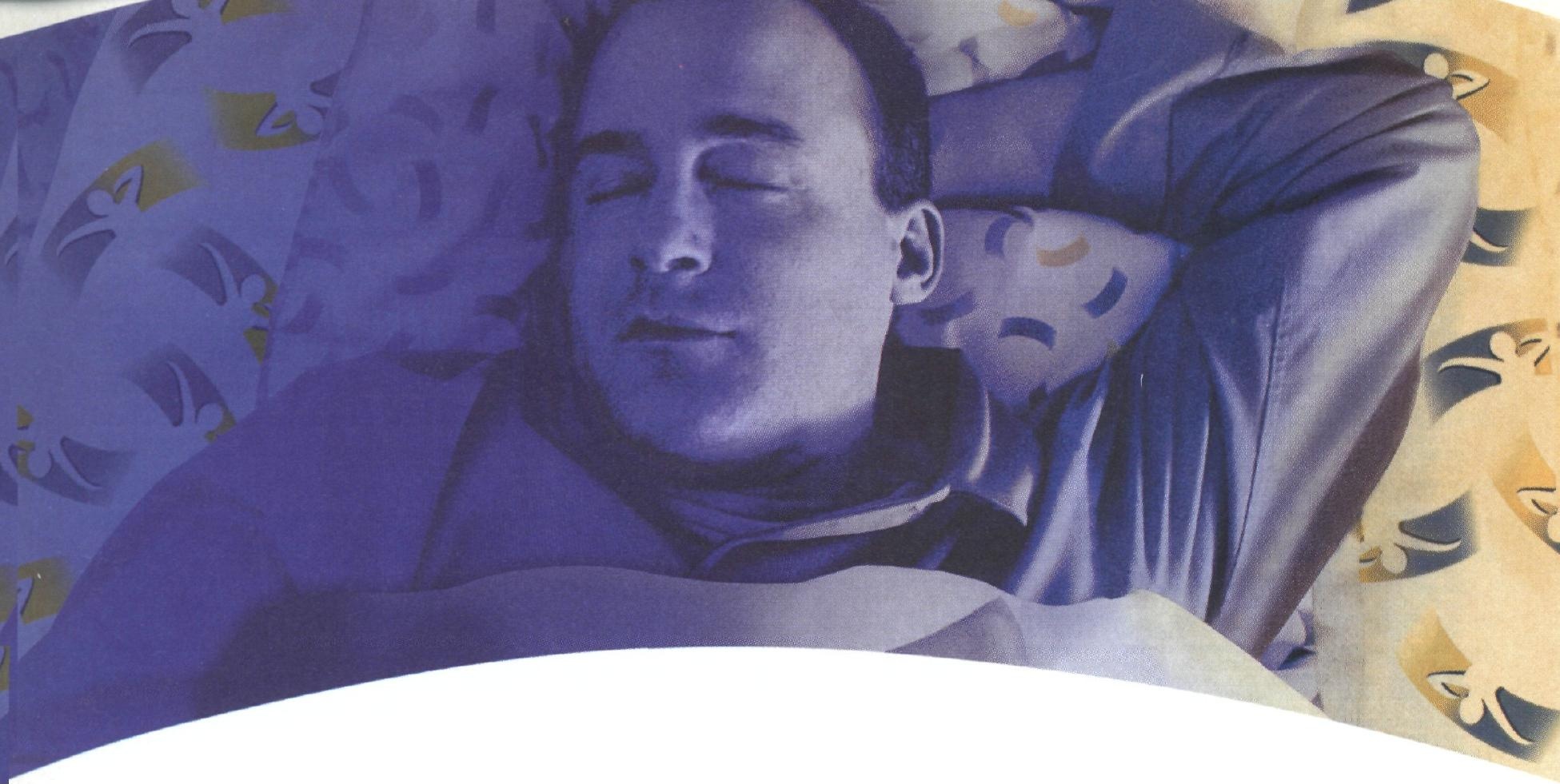

For those patients who just can't sleep...

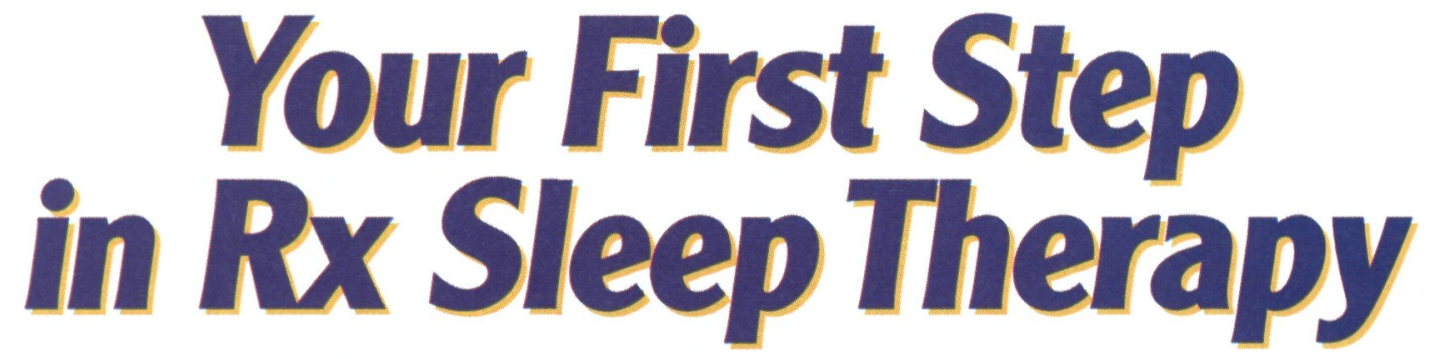

\section{Patients can sleep through the night with the comfort of minimal impairment ${ }^{1,2}$}

SONATA is indicated for the short-term treatment of insomnia.

Although SONATA improved sleep time from baseline in clinical trials, it has not been shown to increase total time slept or decrease awakenings vs placebo.

Patients should remain inactive for 4 or more hours after taking SONATA. Among the most common side effects are headache, dizziness, and somnolence. ${ }^{2}$ Because individuals with a history of addiction to drugs or alcohol are at risk for habituation and dependence, they should be under careful surveillance when receiving SONATA or any other sedative/hypnotic.

Until patients know how they will react to sleep agents, they should not engage in activities requiring mental alertness or motor coordination (e.g., driving or operating machinery) after taking SONATA or any sleep agent. Hypnotics should generally be limited to 7 to 10 days of use, and reevaluation of the patient is recommended if hypnotics are taken for more than 2 to 3 weeks.

References: 1. Elie R, Rüther E, Farr I, et al. Sleep latency is shortened during 4 weeks of treatment with zaleplon, a novel nonbenzodiazepine hypnotic. F Clin Psychiatry. 1999;60:536-544. 2. SONATA ${ }^{\circledR}$ (zaleplon) Prescribing Information, Wyeth-Ayerst Laboratories, Philadelphia, Pa.

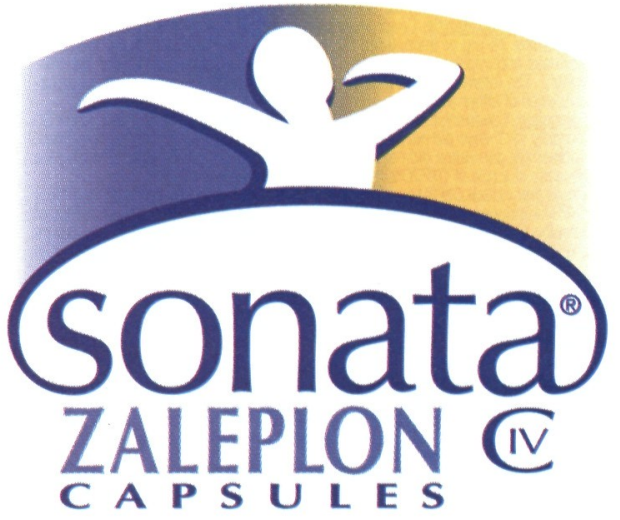

Please visit our Web site at www.sonatasleep.com

Please see brief summary of Prescribing Information on adjacent page. 
Brief Summary

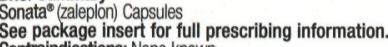

Contraindications: None known. physical and/or psychiatric disorder, symptomatic treatment of insomnia should be after 7 to 10 days of treatment may indicate the presence of a primary psychiatric and/or medical illness that should be evaluated. Worsening of insomnia or the emer-
gence of new thinking or behavior abnormalities may be the consequence of an gence of new thinking or behavior abnormalities may be the conseguence of an
unrecognized psychiatric or physical disorder. Such findings have emerged during the course of peatrant weredse effects of Sonata appear to be dose-related it is important to use the lowest possible effective dose, especially in the elderly. A variety of abnormal thinking and behavior changes have been reported to occur in association with the use of sedative/hypnotics. Some of these changes may be characterized by decreased inhibition (eg, aggressiveness and extroversion that
seem out of character) similar to effects produced by alcohol and other CNS

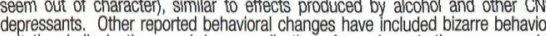
agtation, hallucinations, and depersonalization. Amnesia and other neuropsychiing of depression, including suicidal thinking, has been reported in association with the use of sedative/hypnotics. It can rarely be determined with certainty whether a particular instance of the abnormal behaviors listed above are drug induced, spon-
taneous in origin, or a result of an underlying psychiatric or physical disorder. Nonetheless, the emergence of any new behavioral sign or symptom of concern requires careful and immediate evaluation. Following rapid dose decrease of
abrupt discontinuation of the use of sedative/hypnotics, there have been reports of signs and symptoms similar to those associated with withdrawal from other CNS depressant drugs (see Drug Abuse and Dependence). Sonata, like other hypnotics, has CNS-depressant effects, Because of the rapid onset of action, Sonata
should only be ingested immediately prior to going to bed or after the patient has
gone to bed and has experienced difficulty falling asleen Patients receiving Sonata should be cautioned against engaging in hazardous occupations requiring complete mental alertness or motor coordination (eg, operating machinery or driving a
motor vehicle) after ingesting the drug, including potential impairment of the performance of such activities that may occur the day following ingestion of Sonata. when coadministered with other psychotropic medications, anticonvulsants, antihistamines, eutano, and other drugs that themselves produce coy depression
Sonata should not be taken with alcohol. Dosage adjustment may be necessary
when Sonata is administered with other CNS depressant agents because of the potentially additive effects.

Precautions: GENERAL - Timing of Drug Administration: Sonata should be taken immediately before bedtime or after the patient has gone to bed and has experienced difficulty falling asleep. As with all sedative/hypnotics, taking Sonata while impaired coordination, dizziness, and lightheadedness

Use in the elderly and//or debilitated patients: Impaired motor and/or cognitive pera concern in the treatment of elderly and/or debilitated patients. A dose of $5 \mathrm{mg}$ is recommended for elderly patients to decrease the possibility of side effects. Elderly and/or debilitated patients should be monitored closely, patients with concomitant systemic illness is limited. Sonata should be used with caut depressant effects at hypnotic doses of Sonata in normal subjects, caution should be observed if Sonata is prescribed to patients with compromised respir tory function, because sedative/hypnotics have the capacity to depress respiratochronic obstructive pulmonary disease or moderate obstructive sleep apnea
showed no evidence of alterations in blood gases or apnea/hypopnea index

spectively. However, patients with compromised respiration due to preexisting $\mathrm{mg}$ in patients with mild to moderate hepatic impairment. It is not recommended for use in patients with severe hepatic impairment

No dose adjustment is necessary in patients with mild to moderate renal impair impairment.

Use in patients with depression: As with other sedative/hypnotic drugs, Sonata should be administered with caution to patients exhibiting signs or symptoms of
depression. Suicidal tendencies may be present in such patients and protective measures may be required. Intentional overdosage is more common in this group should be prescribed for the patient at any one time.

printed in the complete p ABORATORY TESTS: There are no specific laboratory tests recommended DRUG INTERACTIONS: CNS-active Drugs- Ethanol: Sonata potentiated the CNSnamic interaction; zaleplon did not affect the pharmacokinetics of ethanol.
Imipramine/Thioridazine: Coadministration of single doses of Sonata $20 \mathrm{mg}$ and mipramine/Thioridazine: Coadministration of single doses of Sonata $20 \mathrm{mg}$ and
imipramine $75 \mathrm{mg}$ or thioridazine $50 \mathrm{mg}$ produced additive effects on decreased alertness and impaired psychomotor performance for 2 to 4 hours after administration. The interaction was pharmacodynamic with no alteration of the pharmacokinetics of either drug.

Paroxetine: Coadministration of a single dose of Sonata $20 \mathrm{mg}$ and paroxetine 20 Additionally, paroxetine did not alter the pharmacokinetics of Sonata, refflecting the absence of a role of CYP2D6 in zaleplon's metabolism.
Orugs that Induce CYP3A4- - Rifampin: Multiple-dose administration of the potent zaleplon $\mathrm{C}_{\text {max }}$ and AUC by approximately $80 \%$. The coadministration of a potent ineffectiveness of zaleplon. Drugs that Inhibit CYP3A4 - The coadministration of a potent, selective CYP3A4 inhibitor is not expected to produce a clinically important pharmacokinetic interac-
tion with zaleplon; however, there are no clinical studies specifically addressing this question. Ins that Inhit Aldehyde Oxidase-Diphenhydramine: Diphenhydramine is macokinetic interaction between zaleplon and diphenhydramine foliowing the

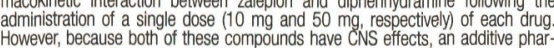
macodynamic effect is possible.

Drugs that Inhibit Both Aldehyde Oxidase and CYP3A4-Cimetidine: Cimetidin inhibits both aldehyde oxidase (in vitro) and CYP3A4 (in vitro and in vivo), the pri-
mary and secondary enzymes, respectively, responsible for zaleplon metabolism. mary and secondary enzymes, respectively, responsible for zaleplon metabolism nould be given to patients who are concomitantly being treated with cimetidine. Drugs Highly Bound to Plasma Protein-Zaleplon is not highly bound to plasma
proteins (fraction bound $60 \% \pm 15 \%$; therefore, the disposition of zaleplon is not expected to be sensittve to alterations in protein binding. In addition, admininstra-
tion of Sonata to a patient taking another drug that is highly protein bound should tion of Sonata to a patient taking another drug that is highly protein bound should not cause transient increase in rree concentrations of the other drug.
Drugs with a Narrow Therapeutic Index - Digoxin: Sonata $(10 \mathrm{mg})$ did not affect the
pharmacokinetic or pharmacodynamic profile of digoxin $(0.375 \mathrm{mg}$ q24h for 8 days).
Warfarin: Multiple oral doses of Sonata ( $20 \mathrm{mg}$ q $24 \mathrm{~h}$ for 13 days) did not affect the pharmacokinetics of warfarin ( $(\mathrm{R}+)^{-}$- or (S-)-enantiomers or the pharmacodynamics (prothrombin time) following a single $25 \mathrm{mg}$ oral dose of warfarin
Drugs that Alter Renal Excretion-lbuprofen: There was no appar

netic interaction between zaleplon and ibuprofen following single dose administra- tion (10 mg and $600 \mathrm{mg}$, respectively) of each drug. This was expected because zaleplon is primarily metabolized, and renal excretion of unchanged zalepton
accounts for less than $1 \%$ of the administered dose.
CARCINOGENESIS. MUAGGENESIS, AND IMPARMENT OFFRTILTY-Carcinogenesis Mice received doses equivalent to $6-49$ times the maximum recommended uman dose (MRHD) of $20 \mathrm{mg}$ on a mg/m² basis. There was a significant increase in the incidence of hepatocellular adenomas in female mice in the high dose group.
Rats received doses equivalent to $0.5-10$ times the MRHD. Zaleplon was not car-

Mutagenesis: Zaleplon was clastogenic when tested for chromosomal aberrations
cinogeni in the in vitro Chinese hamster ovary cell assay, In the in vitro human lymphocyte mutagenic in the Ames bacterial gene mutation assay or the Chinese hamster ovary HGPRT gene mutation assay. Zaleplon was not clastogenic in two in vivo assays, the mouse bone marrow micronucleus assay and the rat bone marrow
chromosomal aberration assay, and did not cause DNA damage in the rat hepatoImpairment of Fertility: In a study in rats, mortality and decreased fertility were associated with administration of an oral dose of zaleplon of $100 \mathrm{mg} / \mathrm{kg} / \mathrm{day}$ to mpaired fertility was due to an effect on the fema

PREGNANCY - Pregnancy Category C: Oral administration of up to 100 and 50 $\mathrm{mg} / \mathrm{kg} / \mathrm{day}$, respectively, to pregnant animals (rats and rabbits) throughout organo-
genesis produced no evidence of teratogenicity. In rats, pre- and postnatal growth was reduced in the offspring of dams receiving $100 \mathrm{mg} / \mathrm{kg} / \mathrm{day}$. This dose was also weight gain during gestation. The no-effect dose for rat offspring growth reduction weight gan during gestation. The no-effect dose for rat offspring growth reduction
was $10 \mathrm{mg} / \mathrm{kg}$ (a dose equivalent to 5 times the MRHD of $20 \mathrm{mg}$ on a mg/m² at the doses examined.

In a pre- and postnatal development study in rats, increased stillbirth and postnatal mortality, and decreased growth and physical development, were observed in
the offspring of females treated with doses of $7 \mathrm{mg} / \mathrm{kg} /$ day or greater during the atter part of gestation and throughout lactation. There was no evidence of matermg/kg/day. When the adverse effects on offspring viability and growth were was in a cross-fostering study, they appeared to result from both in utero and lacThional exposure to the drug.
There are no studies of zaleplon in pregnant women; therefore, Sonata is not recommended for use in women during pregnancy.
LABOR AND DELIVERY: Sonata has no established use in labor and delivery NURSING MOTHERS: A study in lactating mothers indicated that the clearance and
half-life of zaleplon is similar to that in young normal subjects. A small amount of aleplon is excreted in breast milk, with the highest excreted amount occurring duramount of the drug from breast milk may result in potentially important concentra-
tions in infants, and because the effects of zaleplon on a nursing infant are not known, it is recommended that nursing mothers not take Sonata.
PEDIATRIC USE: The safety and effectiveness of Sonata in pediatric patients have not been established. 311 received $5 \mathrm{mg}$ and 317 received $10 \mathrm{mg}$. In both sleep laboratory and these, tient studies, elderly patients with insomnia responded to a 5 -mg dose with a During short-term treatment (14 night studies) of elderly patients with Sonata, no witherse event with a frequency of at least $1 \%$ occurred at a significantly higher rate
with either $5 \mathrm{mg}$ or $10 \mathrm{mg}$ Sonata than with placebo. Adverse Reactions: ADVERSE FNDINGS OBSERVED IN SHORT-TERM, PLACEBOTreatment: In premarketing placebo-controlled, parallel-group phase $2-3$ clinical
trials $3.1 \%$ of 744 patients who received placebo and $3.5 \%$ of 2.069 patients who received Sonata discontinued treatment because of an adverse clinical event. This
difference was not statistically significant. No event that resulted in discontinuatiren occurred at a rate of $\geq 1 \%$. Adverse Events Occurring at an Incidence of $1 \%$ or More Among Sonata $20 \mathrm{M}$ night studies of Sonata at doses of 5 or $10 \mathrm{mg}$ and $20 \mathrm{mg}$, the incidence of treatment emergent adverse events. The table includes only those events that occurred patients treated with Sonata $20 \mathrm{mg}$ was greater than the incidence in placebo-

TABLE 1: Incidence (\%) of Treatment-emergent Adverse Events in Long-term $(28 \mathrm{~N}$

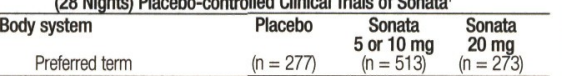

Body as a whole

Abdominal pain
Asthenia

Headach

Photosensitivity reaction

Digestive system

Colitis

Dyspepsia

Nausea

Peripheral edema
Mustional

tal syster

Myalgia
rias system

Amnesia

Anxiety
Depersonalization

Dizziness
Hallucination

Hypesthesia
Paresthesia

Vertig

Respiratory system

Special sense

Abnormal vision

Abnorm
Ear pain
Eye pain

Hyperacusis

Urogenital system

$\begin{array}{rrr}4 & 5 & 6 \\ 5 & 5 & 8 \\ 1 & 2 & 2 \\ 31 & 28 & 38 \\ <1 & <1 & 2\end{array}$
insomnia to a withdrawal syndrome that may include abdominal and muscle observed in two patients, one of whom had a prior seizure, in clinical trials with Sonata. Seizures and death have been seen following the withdrawal of zaleplon from animals at doses many times higher than those proposed for human use. Because individuals with a history of addiction to, or abuse of, drugs or alconol are when receiving Sonata or any other hypnotic. Tolerance: Possible tolerance to the hypnotic effects of Sonata 10 and $20 \mathrm{mg}$ was assessed by evaluating time to sleep onset with Sonata compared with placebo in two placebo-controlled 28 -day studies. No development of tolerance to Sonata was observed for time to sleep onset

OVERDOSAGE: There is limited pre-marketing clinical experience with the effects of an overdosage of Sonata. Two cases of overdose were reported. One was the accidental ingestion by a $21 / 2$ year old boy of $20-40 \mathrm{mg}$ of zaleplon. The second were treated and recovered uneventfully.

Signs and Symptoms: Signs and symptoms of overdose effects of CNS depressants can be expected to present as exaggerations of the pharmacological effects noted in precinical testing. Overdose is usually manifested by degrees of central symptoms include drowsiness, mental confusion, and lethargy: in more serious cases, symptoms may include ataxia, hypotonia, hypotension, respiratory depression, rarely coma, and very rarely death.

supportive measures Intravenous fluids should be administered as needed. Animal studies suggest that flumazenil is an antagonist to zaleplon. However, there is no premarketing clinical experience with the use of flumazenil as an antidote to a Sonata overdose. As in all cases of drug overdose, respiration, pulse, blood pressure, and other appropri-
ate signs should be monitored and general supportive measures employed. Hypotension and CNS mepressio Poison Control Center: As with the management of all overdosage, the possibility of multiple drug ingestion should be considered. The physician may wish to con-
sider contacting a poison control center for up-to-date information on the management of hypnotic drug product overdosage.
Based on Sonata Cl 6001-1 issued August 13, 1999

Events for which the incidence for Sonata $20 \mathrm{mg}$-treated patients was at least
$\%$ and greater than the incidence among placebo-treated patients. Incidence

greater than $1 \%$ has been rounded to the nearest whole number.
DTHER ADVERSE EVENTS OBSERVED DURING THE PREMARKETING EVALUATION OF SONATA: Following is a list of COSTART terms that reflect treatment-emergen

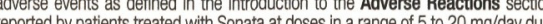
ing premarketing thase 2 and 3 linical trials throughout the 20 nited States, 
In the medical management of ADHD...

\section{FIVE clinically sound reasons to consider ADDERALL ${ }^{\oplus}$ for the ADHD patients}

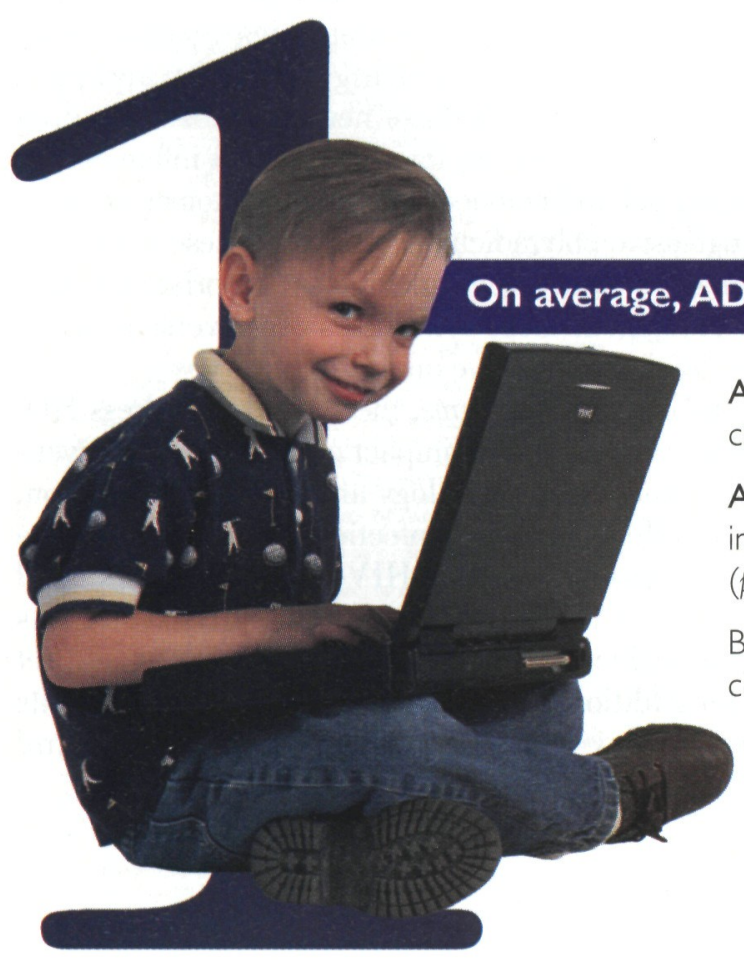
in your practice... clinical staff for continued medication'

ADDERALL produced significantly more improvement in most measures of behavior as compared to Ritalin $(p<0.05)^{*}$

Both drugs produced low and comparable levels of clinically significant side effects'

\section{ADDERALL achieved better scores than methylphenidate (MPH)} in reducing inattentive and hyperactive symptoms $(p<0.05)^{2}$

ADDERALL scored better than MPH $(p<0.05)$ on

Clinical Global Impression (CGI) improvement ${ }^{2}$

Children who obtained a CGI-improvement score of I or 2 were defined as "responders" - and there were significantly more responders in the ADDERALL group as compared to the MPH group $(p<0.01)^{2}$

Side effects were no different than placebo²

Pliszka et al, 2000. ${ }^{2}$

*Except for complaining and positive peer behaviors, in which cases the degree of improvement with ADDERALL was equal to that of Ritalin.

Pelham et al, 1999 .
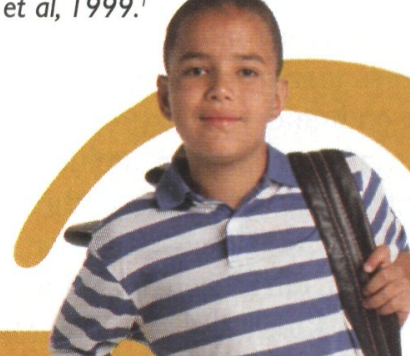
Patients receiving ADDERALL remained on therapy significantly longer than those receiving $\mathrm{MPH}$ - average length of time on initial medication was 153 days for ADDERALL $(p<0.001)$ and 130 days for $\mathrm{MPH}(p=0.0003)^{3}$

Grcevich et al, 1999.3
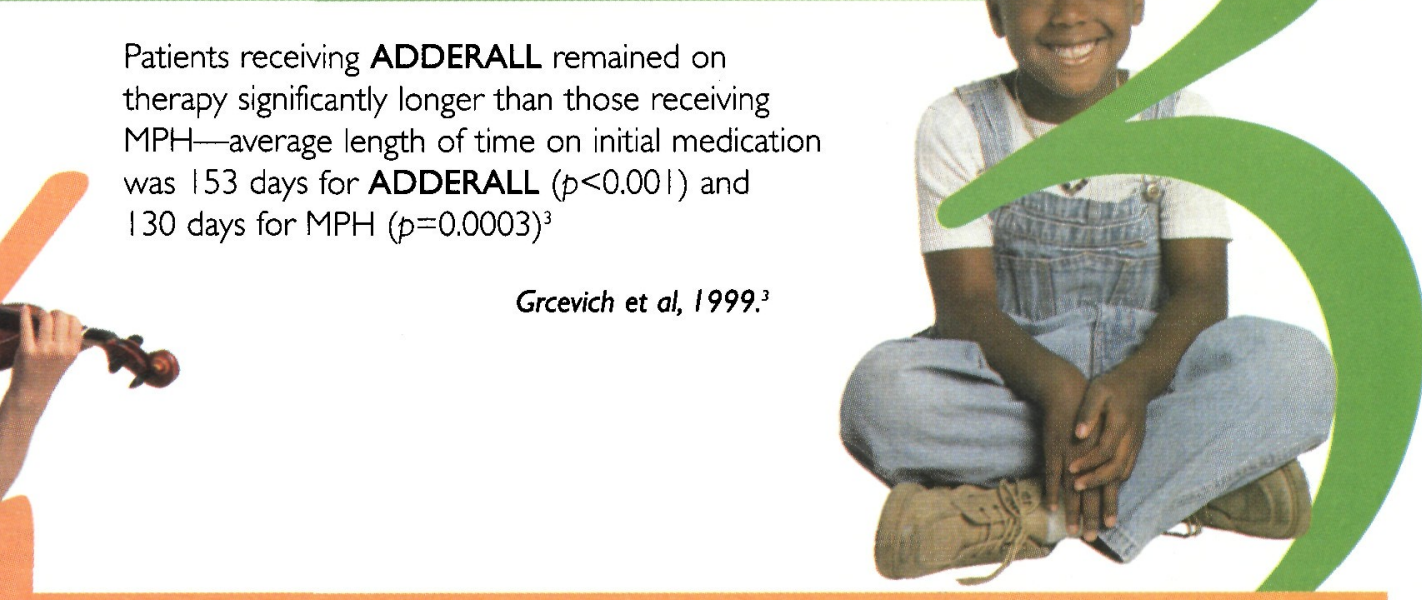

Single-dose treatments of ADDERALL (average $10.6 \mathrm{mg} /$ day) appear to be as effective as 2 daily doses of MPH (average $19.5 \mathrm{mg} /$ day)

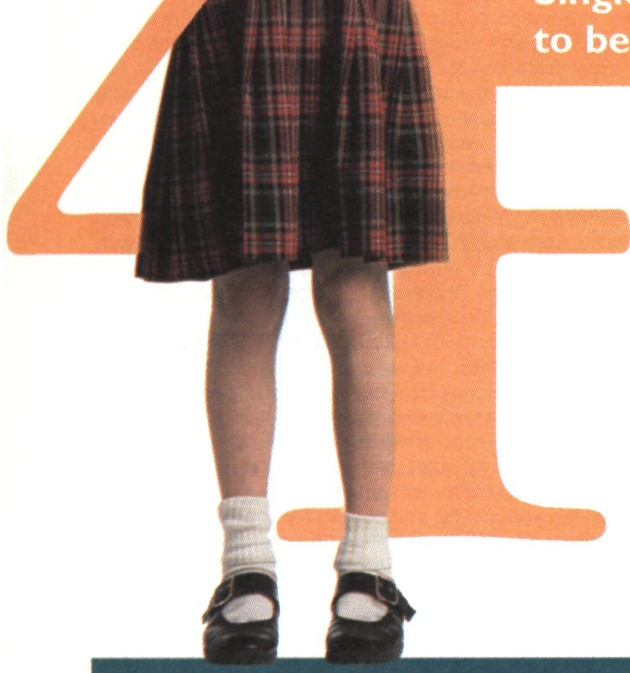

$87 \%$ of MPH failures were successfully treated with ADDERALL ${ }^{4}$

Analysis of side effects data revealed no differences between placebo and best dose. Few children experienced any serious side effects their best dose week ${ }^{4}$

Manos et al, $1999 .^{4}$

Overall effects of ADDERALL on attention and deportment were significant $(p<0.0001)^{5}$

Duration of action increases with dose of ADDERALL

No serious or unusual side effects were noted-measures of side effects were no more frequent or severe in most medication conditions than in the placebo condition ${ }^{5}$

Swanson et al, $1998 .^{5}$

Adderall is generally well tolerated-adverse reactions have seldom been reported (most frequently reported adverse reactions include anorexia, insomnia, stomach pain, beadache, irritability, and weight loss).

As with most psychostimulants indicated for $A D H D$, the possibility of growth suppression and the potential for precipitating motor tics and Tourette's syndrome exist with Adderall treatment and, in rare cases, exacerbations of psychosis bave been reported. Since amphetamines bave a bigh potential for abuse, Adderall should only be prescribed as part of an overall multimodal treatment program for $A D H D$, with close physician supervision.

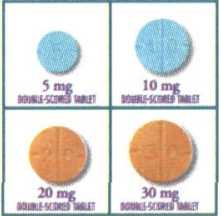

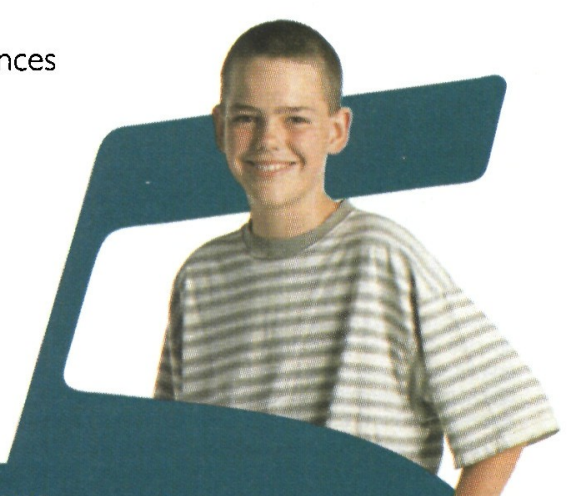

\section{e}$$
\text { . }
$$ 
References: I. Pelham WE, Aronoff HR, Midlam JK, et al. A comparison of Ritalin and Adderall: efficacy and time-course in children with attention-deficit/hyperactivity disorder, Pediatrics [serial online]. 1999;103:e43. Available at: http://www.pediatrics.org/. 2. Pliszka S, Browne RG, Wynne SK, et al. Comparing Adderall and methylphenidate in ADHD. J Am Acad Child Adolesc Psychiatry. 2000. In press. 3. Grcevich S, Rowane WA, Marcellino B, et al. Assessing the clinical practice of prescribing Adderall vs. methylphenidate to children with attention-deficit disorder. APA Annual Meeting, May 15-20, 1999. Washington DC. 4. Manos MJ, Short EJ Findling RL. Differential effectiveness of methylphenidate and Adderall ${ }^{\Phi}$ in school-age youths withattention-deficit/hyperactivity disorder.J Am Acad Child Adolesc Psychiatry. 1999:38(7):813-819.5. Swanson J, Wigal S, Greenhill L, et al. Analog classroom assessment of Adderall in children with ADHD. J Am Acad Child Adolesc Psychiatry. 1998;37(5):519-525.

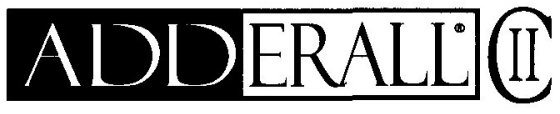

$5 \mathrm{mg}, 10 \mathrm{mg}, 20 \mathrm{mg} \& 30 \mathrm{mg}$ TABLETS (Mixed Salts of a Single-Entity Amphetamine Product) Amphetamine Sulfate
Dextroamphetaminetamine Sulfate

\section{adderall ${ }^{\circledR}$ TABlets (11. Brief summary}

\begin{abstract}
AMPHETAMINES HAVE A HIGH POTENTIAL FOR ABUSE. ADMINISTRATION OF AMPHETAMINES FOR PROLONGED PERIODS OF TIME MAY LEAD TO DRUG DEPENDENCE AND MUST BE AVOIDED. PARTICULAR ATTENTION SHOULD BE PAID TO THE POSSIBILITY OF SUBJECTS OBTAINING AMPHETAMINES FOR NONTHERAPEUTIC USE OR DISTRIBUTION TO OTHERS, AND THE DRUGS SHOULD BE PRESCRIBED OR DISPENSED SPARINGLY.
\end{abstract}

INDICATIONS: Attention Deficit Dlsorder with Hyperactivity: ADDERALL is indicated as an integral part of a total treatment program which typically includes other remedial measures (psychological, educational, social) for a stabilizing effect in children with behavioral syndrome characterized by the following group of developmentally inappropriate symptoms: moderate to severe distractibility, short attention span, hyperactivity, emotional lability, and impulsivity. The diagnosis of this syndrome should not be made with finality when these symptoms are only of comparatively recent origin. Nonlocalizing (soft) neurological signs, learning disability and abnormal EEG may or may not be present, and a diagnosis of central nervous system dysfunction may or may not be warranted. In Narcolepsy: CONTRAINDICATIONS: Advanced arteriosclerosis, symptomatic cardiovascular disease, moderate to severe hypertension, hyperthyroidism, known hypersensitivity or idiosyncrasy to the sympathomimetic amines, glaucoma. Agitated states. Patients with a history of drug abuse. During or within 14 days following the administration of monoamine oxidase inhibitors (hypertensive crises may result). WARNINGS: Clinical experience suggests that in psychotic children, administration of amphetamine may exacerbate symptoms of behavior disturbance and thought disorder. Data are inadequate to determine whether chronic administration of amphetamine may be associated with growth inhibition; therefore, growth should be monitored during treatment. Usage in Nursing Mothers: Amphetamines are excreted in human milk. Mothers taking amphetamines should be advised to refrain from nursing. PRECAUTIONS: General: Caution is to be exercised in prescribing amphetamines for patients with even mild hypertension. The least amount feasible should be prescribed or dispensed at one time in order to minimize the possibility of overdosage. Information for Patients: Amphetamines may impair the ability of the patient to engage in potentially hazardous activities such as operating machinery or vehicles; the patient should therefore be cautioned accordingly. Drug Interactions: Acidifying agents Gastrointestinal acidifying agents (guanethidine, reserpine, glutamic acid $\mathrm{HCl}$, ascorbic acid, fruit juices, etc.) lower absorption of amphetamines. Urinary acidifying agents (ammonium chloride, sodium acid phosphate, etc) Increase the concentration of the ionized species of the amphetamine molecule, thereby increasing urinary excretion. Both groups of agents lower blood levels and efficacy of amphetamines. Adrenergic blockers - Adrenergic blockers are inhibited by amphetamines. Alkalinizing agents - Gastrointestinal alkalinizing agents (sodium bicarbonat $\theta$, etc.) increase absorption of amphetamines. Urinary alkalinizing agents (acetazolamide, some thiazides) increase the concentration of the nonionized species of the amphetamine molecule, thereby decreasing urinary excretion. Both groups of agents increase blood levels and therefore potentiate the actions of amphetamines. Antidepressants, tricyclic - Amphetamines may enhance the activity of tricyclic or sympathomimetic agents; $d$-amphetamine with desipramine or protriptyline and possibly other tricyclics cause striking and sustained increases in the concentration of $d-$ amphetamine in the brain cardiovascular effects can be potentiated. MAO inhibitors - MAOI antidepressants, as well as a metabolite of furazolidone, slow amphetamine metabolism. This slowing potentiates amphetamines, increasing their effect on the release of norepinephrine and other monoamines from adrenergic nerve endings; this can cause headaches and other signs of hypertensive crisis. A variety of neurological toxic effects and malignant hyperpyrexia can occur, sometimes with fatal results. Antihistamines Amphetamines may counteract the sedative effect of antihistamines. Antihypertensives Amphetamines may antagonize the hypotensive effects of antihypertensives Chlorpromazine - Chlorpromazine blocks dopamine and norepinephrine reuptake, thus inhibiting the central stimulant effects of amphetamines, and can be used to treat amphetamine poisoning. Ethosuximide - Amphetamines may delay intestinal absorption of ethosuximide. Haloperidol - Haloperidol blocks dopamine and norepinephrine reuptake, thus inhibiting the central stimulant effects of amphetamines. Lithium carbonate - The anorectic and stimulatory effects of amphetamines may be inhibited by lithium carbonate. Meperidine Amphetamines potentiate the analgesic effect of meperidine. Methenamine therapy Urinary excretion of amphetamines is increased, and efficacy is reduced, by acidifying agents used in methenamine therapy. Norepinephrine - Amphetamines enhance the adrenergic effect of norepinephrine. Phenobarbital - Amphetamines may delay intestina absorption of phenobarbital; co-administration of phenobarbital may produce a synergistic anticonvulsant action. Phenytoin - Amphetamines may delay intestinal absorption of phenytoin; co-administration of phenytoin may produce a synergistic anticonvulsant action Propoxyphene - In cases of propoxyphene overdosage, amphetamine CNS stimulation is potentiated and fatal convulsions can occur. Veratrum alkaloids - Amphetamines inhibit the hypotensive effect of veratrum alkaloids. Drug/Laboratory Test Interactions: • Amphetamines can cause a significant elevation in plasma corticosteroid levels. This increase is greatest in the evening. - Amphetamines may interfere with urinary steroid determinations. Carclnogenesis/Mutagenesis: Mutagenicity studies and long-term studies in animals to determine the carcinogenic potential of amphetamine, have not been performed. Pregnancy - Teratogenic Eftects: Pregnancy Category C. Amphetamine has been shown to have embryotoxic and teratogenic effects when administered to $A / J a x$ mice and $\mathrm{C} 57 \mathrm{BL}$ mice in doses approximately $\mathbf{4 1}$ times the maximum human dose. Embryotoxic effects were not seen in New Zealand white rabbits given the drug in doses 7 times the human dose nor in rats given 12.5 times the maximum human dose. While there are no adequate and well-controlled studies in pregnant women, there has been one report of severe congenital bony deformity, tracheoesophageal fistula, and anal atresia (vate association) in a baby born to a woman who took dextroamphetamine sulfate with lovastatin during the first trimester of pregnancy. Amphetamines should be used during pregnancy only if the potential benefit justifies the potential risk to the fetus. Nonteratogenic Effects : Infants born to mothers dependent on amphetamines have an increased risk of premature delivery and low birth weight. Also, these infants may experience symptoms of withdrawal as demonstrated by dysphoria, including agitation, and significant lassitude. Pediatric Use: Long-term effects of amphetamines in children have not been well established. Amphetamines are not recommended for use in children under 3 years of age with Attention Deficit Disorder with Hyperactivity described under INDICATIONS AND USAGE. Amphetamines have been reported to exacerbate motor and phonic tics and Tourette's syndrome. Therefore, clinical evaluation for tics and Tourette's syndrome in children and their families should precede use of stimulant medications. Drug treatment is not indicated in all cases of Attention Deficit Disorder with Hyperactivity and should be considered only in ight of the complete history and evaluation of the child. The decision to prescribe amphetamines should depend on the physician's assessment of the chronicity and severity of the child's symptoms and their appropriateness for his/her age. Prescription should not depend solely on the presence of one or more of the behavioral characteristics. When these symptoms are associated with acute stress reactions, treatment with amphetamines is usually not indicated. ADVERSE REACTIONS: Cardiovascular: Palpitations, tachycardia, elevation of blood pressure. There have been isolated reports of cardiomyopathy associated with chronic amphetamine use. Central Nervous System: Psychotic episodes at recommended doses (rare), overstimulation, restlessness, dizziness, insomnia, euphoria, dyskinesia, dysphoria, tremor, headache, exacerbation of motor and phonic tics and Tourette's syndrome. Gastrointestinal: Dryness of the mouth, unpleasant taste, diarrhea constipation, other gastrointestinal disturbances. Anorexia and weight loss may occur as undesirable effects when amphetamines are used for other than the anorectic effect. Allergic: Urticaria. Endocrine: Impotence, changes in libido. DRUG ABUSE AND DEPENDENCE: Dextroamphetamine sulfate is a Schedule II controlled substance. Amphetamines have been extensively abused. Tolerance, extreme psychological dependence, and severe social disability have occurred. There are reports of patients who have increased the dosage to many times that recommended. Abrupt cessation following prolonged high dosage administration results in extreme fatigue and mental depression; changes are also noted on the sleep EEG. Manifestations of chronic intoxication with amphetamines include severe dermatoses, marked insomnia irritability, hyperactivity, and personality changes. The most severe manifestation of chronic intoxication is psychosis, often clinically indistinguishable from schizophrenia. This is rare with oral amphetamines. OVERDOSAGE: Individual patient response to amphetamines varies widely. While toxic symptoms occasionally occur as an diosyncrasy at doses as low as $2 \mathrm{mg}$, they are rare with doses of less than $15 \mathrm{mg} ; 30 \mathrm{mg}$ can produce severe reactions, yet doses of 400 to $500 \mathrm{mg}$ are not necessarily fatal. In rats the oral $L D_{50}$ of dextroamphetamine sulfate is $96.8 \mathrm{mg} / \mathrm{kg}$. Symptoms: Manifestations of acute overdosage with amphetamines include restlessness, tremor, hyperreflexia, rapid espiration, confusion, assaultiveness, hallucinations, panic states, hyperpyrexia an habdomyolysis. Fatigue and depression usually follow the central stimulation. Cardiovascular effects include arrhythmias, hypertension or hypotension and circulator collapse. Gastrointestinal symptoms include nausea, vomiting, diarrhea, and abdomina cramps. Fatal poisoning is usually preceded by convulsions and coma. Treatment: Consult with a Certified Poison Control Center for up to date guidance and advice. Management of acute amphetamine intoxication is largely symptomatic and includes gastric lavage administration of activated charcoal, administration of a cathartic and sedation. Experience with hemodialysis or peritoneal dialysis is inadequate to permit recommendation in this regard. Acidification of the urine increases amphetamine excretion, but is believed to increase risk of acute renal failure if myoglobinuria is present. If acute, severe hypertension complicates amphetamine overdosage, administration of intravenous phentolamine (Regitine ${ }^{\circ}$, Novartis) has been suggested. However, a gradual drop in blood pressure will usually result when sufficient sedation has been achieved. Chlorpromazine antagonizes the central stimulant effects of amphetamines and can be used to treat amphetamine intoxication. DOSAGE AND ADMINISTRATION: Regardless of indication, amphetamines should be administered at the lowest effective dosage and dosage should be individually adjusted. Late evening doses should be avoided because of the resulting insomnia. Attention Deficit Disorder with Hyperactivity: Not recommended for children under 3 years of age. In children from 3 to 5 years of age, start with $2.5 \mathrm{mg}$ daily; daily dosage may be raised in increments of $2.5 \mathrm{mg}$ at weekly intervals until optimal response is obtained. In children 6 years of age and older, start with $5 \mathrm{mg}$ once or twice daily; daily dosage may be raised in increments of $5 \mathrm{mg}$ at weekly intervals until optimal response is obtained. Only in rare cases will it be necessary to exceed a total of $40 \mathrm{mg}$ per day. Give first dose on awakening; additional doses ( 1 or 2 ) at intervals of 4 to 6 hours. Where possible, drug administration should be interrupted ccasionally to determine if there is a recurrence of behavioral symptoms sufficient to require continued therapy. Narcolepsy: Usual dose $5 \mathrm{mg}$ to $60 \mathrm{mg}$ per day in divided doses, depending on the individual patient response. Narcolepsy seldom occurs in children under 12 years of age; however, when it does, dextroamphetamine sulfate may be used. The suggested initial dose for patients aged 6-12 is $5 \mathrm{mg}$ daily; daily dose may be raised in increments of 5 $\mathrm{mg}$ at weekly intervals until optimal response is obtained. In patients 12 years of age and older, start with $10 \mathrm{mg}$ daily; daily dosage may be raised in increments of $10 \mathrm{mg}$ at weekly intervals until optimal response is obtained. If bothersome adverse reactions appear ( e.g., insomnia or anorexia), dosage should be reduced. Give first dose on awakening; additional doses (1 or 2) at intervals of 4 to 6 hours. Rx only.

\section{Shire Richwood Inc.}




\section{UIIHOBII

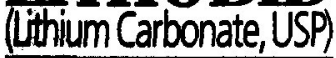 \\ Smooth, slow release of lithium carbonate for initial or maintenance treatment of mania associated with bipolar disorder}

Buf Eummery for ful Prescribing Information and Pattent information, refer to package insert.)

\section{WARNING}

Whitum toxclty is closely related to serum lithlum levels, and can occur at doses close to therapeutic levels. Facilitlos for prompt and accurate serum lithium determinations should be avaliable before
intlating therey (see DOSAGE AND ADMMNISTAATION).

\section{MDICATION8}

Lithum Is indicated in the treatment of manic episodes of manic-depressive iliness. Maintenance therapy prevents or dininlahes the intensity of subsequent episodes in those manic-depressive patients with a hlstory of mania.

Typleal eymptoms: of mania indude pressure of speech, motor hyperactivity, reduced neөd for sleep, filght of ideas grendiosty, elation, poor Judgment, aggressiveness, and possbbly hostlity. When given to a patient experiencing a manic episode, lithlum may produce a normalization of symptomatology within 1 to 3 weeks.

\section{WARNMES}

Lithim should generally not be given to patients with significant renal or cardiovascular disease, severe deblittatlon, dehydration, sodum depletion, and to pattents receiving diuretics, or angiotensin converting enzyme (ACE) inhibltors, since the risk of lith um toxclity is very high in such patients. If the psychiatric indlcation is life threatening, and if such a petient falis to respond to other measures, ithium treatment may be undertaken with extreme caution, including dally a petient falls to respond to other measures, ithium treatment may be undertaken with extreme caution, including daly
serum hithlum determinations and adjustment to the usually low doses ordinarly tolerated by these indlviduals. In such instances, hospltallzation is a necesslty.

Chronlc lithium therapy may be associated with diminution of renal concentrating ability, occaslonally presenting as nephrogenlc dabetes hsiplous, wth polyuria and polydipsta. Such patients should be carefully managed to avoid dehycration with resulting lithium retenton and toxicity. This condition is usually reversible when lithium is dlsconthued. Mophologlc changes with glomerular and interstitial fibrosis and nephron atrophy have been reported in patients on chronic lthium therapy. Morphologic changes have also been seen in manic-depressive patients never exposed to
Whitum. The relationship between renal function and morphologic changes and thetr assoclation with lithlum therapy lthimm. The relationship belw
have not been establshed.

Kidney function should be assessed prior to and during lithium therapy. Routine urinalysis and other tests may be used to evaluate tubular function $(\theta .9$. , urine specific gravity or osmolality following a perlod of water deprivation, or 24-hour urhe volume) and glomenuar unction (e.g., serum creatnine or creatinine dearance). During lith um therapy progressive or sudden changes in renal function, even within the normal range, indicate the need for reovaluation of treatment An encephalopathic syndrome (characterized by weakness, lethargy, fever, tremulousness and confuston, extrapyraAn encephalopathic syndrome (characterized by weakness, lethargy, fever, tremulousness and confusion, extrapyra-
midal symptorns, leukocytosis, devated serum enzymes, BUN and FBS) has occurred in a few patients treated with midal symptorns, leukocytosis, elevated serum enzymes, BUN and FBS) has occurred in a fow patients treated with damage. Because of a possible causal relationship between these events and the concomitant administration of damage. Because of a possible causal relationship between these events and the concomitant acministration of
lithium and neuroleotic drugs, patlents recelving such combined therapy or patients wth organic brain syndrome or Ithium and neuroleptic dnugs, patlents receiving such combined therapy or patients with organic brain syndrome or
other CNS Impaiment should be monitored closely for earty evidence of neurologic toxicly and treatment disconthusd prompty if such signs appear. This encephalopathic syndrome may be similar to or the same as disconthusd prompty if such signs aaper

Lithlum toxicly is closely related to serum lithlum concentrations and can occur at doses close to the therapeutio concentrations (SOe DOSAGE AND ADMINISTRATION).

Outpatients and their famllies should be warned that the patient must discontinue lithium therapy and contact his physician if such clinical slgns of lithlum toxicty as dlarthea, vomiting, tremor, mild ataxia, drowsiness, or muscular weakness occur.

Lthum may profong the effects of neurcmuscular blocking agents. Therefore, neuromuscular blocking agents should be given with cautlon to patients receiving lithium.

Uasge in Pregnancy: Adverse effects on nildation in rats, embryo viablity in mice, and metabolism in vitro of rat testis and human spermatozca have been attributed to lithium, as have teratogenicity in submammalian species and cleft palate in mice.

In humans, lthium may cause fetal harm when administered to a pregnant woman. Data from lithium birth registries suggest an Increase in cardlac and other anomalles especially Ebstein's anomay. If this drug is used in women of childbearing potential, or during pregnancy, or if a patient becomes pregnant while taking this drug, the patient should be apprised by their physician of the potential hazard to the fetus.

Usage in Nureing Mothers: Lthium is excreted in human milk. Nursing should not be undertaken during lithilum therapy except in rare and unusual circumstances where, in the view of the physician, the potential benefits to the mother outweigh possible hazard to the infant or neonate. Signs and symptoms of lthium toxicity such as hypertonia, hypothemia, eyanosis and ECG changes have been reported in some infants and neonates.

Podiatrle Use: Safety and effectiveness in pediatric patlents under 12 years of age have not been determined; its use in these patients is not recommended.

There has been a report of transient syndrome of acute dystonia and hyperreflexla occurring in a $15 \mathrm{~kg}$ pediatric patient who ingested $300 \mathrm{mg}$ of Ilthilum cartonate.

\section{PRECAUTIONS}

The ablity to tolerate lithium Is greater during the acute manic phase and decreases when manic symptoms subside (SQ0 DOSAGE AND ADMINISTRATION)

The distribution space of lithium approximates that of total body water. Lithium is primarily excreted in urine with insignlificant excretion in feces. Renal excretion of lithium is proportional to its plasma concentration. The elimination half-life of lithium is approximately 24 hours. Lthium decreases sodlum reabsorption by the renal fubules which could lead to sodlum depletion. Therefore, it is essential for the patient to maintain a normal diet, including salt, and an adequate fluid intake (2500-3500 mL) at least during the initial stabilization period. Decreased tolerance to lithium has been reported to ensue trom protracted sweating or dlarhea and, if such occur, supplemental fluld and salt should be reported to ensue from protracted sweating or dlambea and, if such occur, supplemental fild and sait should be in addition to sweating and diarnea, concomitant intection with elevated temperatures may also necessitate a In addition to swbating and diarnea, concom

Previously existing thyroid disorders do not necessarly constitute a contraindication to lithium treatment. Where mypothyroidsm preaxists, careful monitoring of thyrold function during lithium stabilzation and maintenance allows for correctlon of changhng thyroid parameters and/or adjustment of lithium doses, if any. If hypothyroidism occurs during lithlum stabilzation and maintenance, supplemental thyroid treatment may be used.

In general, the concomitant use of diurettcs or angiotensin corverting enzyme (ACE) inhibitors with lithium cartonate should be avolded. In those cases where concomitant use is necessary, extreme caution is advised since sodlum loss from these dugs may reduce the renal ciearance of lithium resulting in increased serum lithlum concentrations with the ilsk of lithium toxdchy. When such combinations are used, the lithium dosage may noed to be decreased, and more Concomitant administration of carbamazepine and lithium may increase the risk of neurotoxic side effects.

The following drugs can lower serum lithlum concentrations by Increasing urinary lithlum excretion: acetazolamide, urea, xanthine preparations and alkalnizing agents such as sodlum bicarbonate.

Concomitant extended use of lodide preparations, especlally potassium iodide, with lithium may produce hypothyroldism. Indomethacin and piroxicam have been reported to significantly increase steady state serum lithlum concentrations. In some cases lithlium toxicly has resulted from such interactions. There is also some evidence that other nonstercidal, anti-inillammatory agents may have a simllar effect. When such comblnations are used, increased serum lithlum concentration monttoring is recommended.

Concurrent use of calcum channel blocking agents with lithium may increase the rlsk of neurotoxlcity in the form o ataxla, tremors, nausea, vornlting, diarthea and/or tinnitus. Concurrent use of metronidazole with lithium may provok lithlum toxidity due to reduced renal clearance. Patlents recoving such comblned therepy should be monitored closely Concurrent use of fluoxethe with lithium has resulted in both increased and decreased serum lithium concentrations. Patients recelving suet combined therapy should be montored closely.

Lthlum may Impalr mental and/or physical abllities. Patients should be cautloned about activities requirng alertness (6.8., operating vehicles or machinery).

Usage in Pregnency: Pregnancy Category D. (seo WARNING8).

Usage in Nursing Mothers: Because of the potental for serious acverse reactions in nursing intants and neonates from lithlum, a decision should be made whether to dlscontinue nursing or to dlscontinue the drug, taking into account the importance of the drug to the mother (seo WARNINGS)

Pediatric Use:

Uaage In the Elderly: Elderly pattents often require lower lithium dosages to achleve therapeutle serum concentrations. They may also exhibit adverse reactions at serum concentrations ordinarily tolerated by younger patients. Additionally, patients with renal impalment may also require lower lthium doses (see WARNINGS).

\section{ADVERSE REACTIONS}

The occurrence and severtty of adverse reactons are generally drectly related to serum lithium concentratlons and to indwidual patient sensittwity to lithlum. They generally occur more frequently and with greater severlty at higher concentrations.

Adverse reactions may be encountered at serum lithlum concentrations below $1.5 \mathrm{mE} / \mathrm{L}$. Mild to moderate adverse reactions may occur at concentrattons from $1.5-2.5 \mathrm{mEg} / \mathrm{L}$, and moderate to severe raactions may be seen at concentrations trom $2.0 \mathrm{mEg} / \mathrm{L}$ and above.

Fine hand tremor, polyuria and mild thirst may occur during Intial therepy for the acute manle phase, and may persist throughout treatment. Transient and milld nausea and general discomfort may also appear during the first few days of lithium administration.

These side effects usually subside with continued treatment or with a temporary reduction or cessation of dosage. If persistent, a cessation of lithlum therapy may be reculred. Diernea, vorniting, drowsiness, muscular weakness and lack of coordination may be early signs of lithium Intoxication, and can occur at lthlum concentrations below 2.0 mEgh At At higher concentrations giddiness, ataxa, blurred vision, thnitus and a large output of dilute urine may be seen. Serum lithium concentrations above $3.0 \mathrm{mE}$ o/ may produce a complex cllnical picture involving multiple organs and organ systems. Serum lithium concentratlons should not be permitted to exceed $2.0 \mathrm{mEQ} / \mathrm{L}$ during the acute treatment phase.

The following reactions have been reported and appear to be retated to serum lthlum concentrations, induding concentrations within the therapeutic range:

Central Nervous System: tremor, muscle hyperinitabllty (fasciculations, twitching, donic movements of whole limbs) hypertonicity, ataxia, choreoathetotlc movements, hyperactive deep tendon reflex, extrapyramidal symptoms including acute dystonla, cogwheel rigidity, blackout spells, eplieptlform seizures, sturred speech, dizziness, vertigo, downbeat nystagmus, inconthence of unh or feces, somnotence, psychomotor retardation, restlessness, contuslon stupor, coma, tongue movements, tics, tinnitus, hallucinations, poor memory, slowed intellectual functioning, started response, worsening of organlc brain syndromes, Cases of Fseudotumor Cerebri (increased intracranlal pressure and papilledema) have been reported with lithium use, If undetected, this condtlon may result in enlargement of the bling spot, constrictlon of visual fields and eventual blindness due to optic atrophy. Lthium should be discontinued, clinically possible, if this syndrome occurs. Candiovascular, cardlac arthythmia, hypotension, peripheral circulatory collapse, bradycardla, sinus node dystunction with severe bradycardla (which may result in syncope) Gastrolntestinal: anofexla, nausea, vomiting, diarnhea, gastrits, sallvary gland swelling, abdominal pain, excessive salvation, flatulence, indigestion; Genltournary: glycosurla, decreased creatinine clearence, albuminuria, oliguria, an symptoms of nephrogenle dlabetes insipidus including polvuria, thirst and polydipsla; Dermatologic: drying and thinning of halr, alopocia, anesthesia of skin, acne, chronlc follicultis, xerosis cutts, psoriasis or lis exacerbation, generalized pruritus with or without rash, cutaneous ulcers, angloedema; Autonomio Nervous syetem: blured vision dry mouth, impotence/sexual dystunction; Thyrold Abnomedittes: euthyroid golter and/or hypothyroidlsm (induding myxedema) accompanled by lower $T_{3}$ and $T_{4}$ " ${ }^{3}$ lodine uptake may be slevated (soe PRECAUTNONS). Paradoxically, rare cases of hyperthyroidlsm have been reported. EEG Changes: diffuse slowing, widening of trequency spectrum, potentlation and disorganization of background ityith. EKG Chengess reversible flattening, isoelectricty or inversion of T-waves. Miscellaneous: Fatlgue, lethargy, transient scotomata, exophthalmos, dehydration, welght loss, leucocytosis, headache, transtent hyperglycernia, hypercalcemha, hyperparathyroldlsm, albuminuria, excessive weight galn, edematous sweling of ankles or wrists, metallic taste, dysgeusia/taste distortlon, sally

tightness in chest, swollen and/or painful Joints, fever, polyarthralgla, and dental caries. dome reports of nephrogenic diabed

A few reports have been received of the development of painful discoloratlon of fingers and toes and coldness of the extremities within one day of starting lithium treatment. The mechanism through whlch these symptoms (resembing Raynaud's Syndrome) developed is not known. Recovery followed dlscontinuance.

\section{OVERDOSAGE}

The toxic concentrations for lithlum (21.5 mEq/L) are close to the therapeutle concentrations $(0.6-1.2 \mathrm{mE} / \mathrm{L})$. It is therefore important that patients and their familles be cautioned to watch for early toxic symptoms and to discontinue the
REACTIONS.)

Treatment: No specific antidote for lithium poisoning is known. Treatment is supportive. Earty symptoms of llthium tox iclty can usually be treated by reduction or cessation of dosage of the ding and resumption of the treatment at a lower dose after 24 to 48 hours. In severe cases of lithium poisoning, the first and foremost goal of treatment consists of ellimination of this ion from the patient.

Treatment is essentially the same as that used in barblturate poisoning: 1) gestric lavage, 2) correction of frudd and electrolyte imbalance and, 3) regulation of kldney functioning. Urea, mannlitol, and aminophylihe all produce signlifican increases in lithlum excretion. Hemodialysis is an effective and rapid means of removing the ion from the severely toxlc patient. However, patient recovery may be stow.

infectlon prophylaxls, regular chest $X$-rays, and preservation of adequate resplratlon are essential.

DOSAGE AND ADMINISTRATION

Acuto Menia: Optimal patient response can usually be established with $1800 \mathrm{mo} / \mathrm{day}$ in the following dosages:

LTHOBID Slow-Release Tablets': Morning dose of 3 tabs (900 mg); Nlghttme dose of 3 tabs (900 mg)

'Can also be administered on $600 \mathrm{mg}$ t.l. d. recommended dosing interval.

Such doses will normally produce an effectve serum lithium concentration ranging between 1.0 and $1.5 \mathrm{mEgh}$ Dosage must be indlvidualized according to serum concentrations and cllical response. Regular monltoring of the patient's clinical state and of serum lithium concentrations is necessary. Serum concentratons should be determlned twice per week during the acute phase, and untl the serum concentratlons and clinical condition of the patient have been stabilized.

Long-Term Control: Desirable senum lithlum concentratlons are 0.6 to $1.2 \mathrm{mEq} / \mathrm{L}$, whlch can usually be achieved with $900-1200 \mathrm{mg} /$ day. Dosage will vary from one indludual to another, but generally the following dosages whl maintal

LITHOBID Slow-Release Tablets': Morning dose of 2 tabs ( $600 \mathrm{mg}$ ); Nighttlme dose of 2 tabs $(600 \mathrm{mg})$ 'Can be administered on t.l.d. recommended dosing interval up to $1200 \mathrm{mg} /$ day.

Serum lithlum concentratlons in uncomplicated cases recelving maintenance therapy during remission should be monitored at least every two months. Patients abnormally sensitive to lithlum may exhiblt toxic signs at serum concentrators of 1.0 to $1.5 \mathrm{mEqL}$. Elderly patients often respond to reduced dosage, and may $\theta$ xhibitt signs of toxiclty at serum concentrations ordinarlly tolerated by other patents.

N.B.: Blood samples for serum lithium determinations should be drawn Immediately prlor to the next dose when lith um concentrations are relatively stable (1.e., 8-12 hours after previous dose). Total rellance must not be placed on Serum concentrattons alone. Accurate patient evaluation requires both chlice.
Slow-Release Tablets must be swallowed whole and never chewed or crushed.

Solvay

Phermaceuticals

Rev 4/98 (1E-1)

Rolerence: 1. Kirkwood CK, Wilson SK, Hayes PE, et al, Single-dose bloavalablitity of two extended-relsase Ithium carbonate products. Am J Hosp Pham. 1994;51:486-489. Solvay January 1999 Pharmaceuticals 


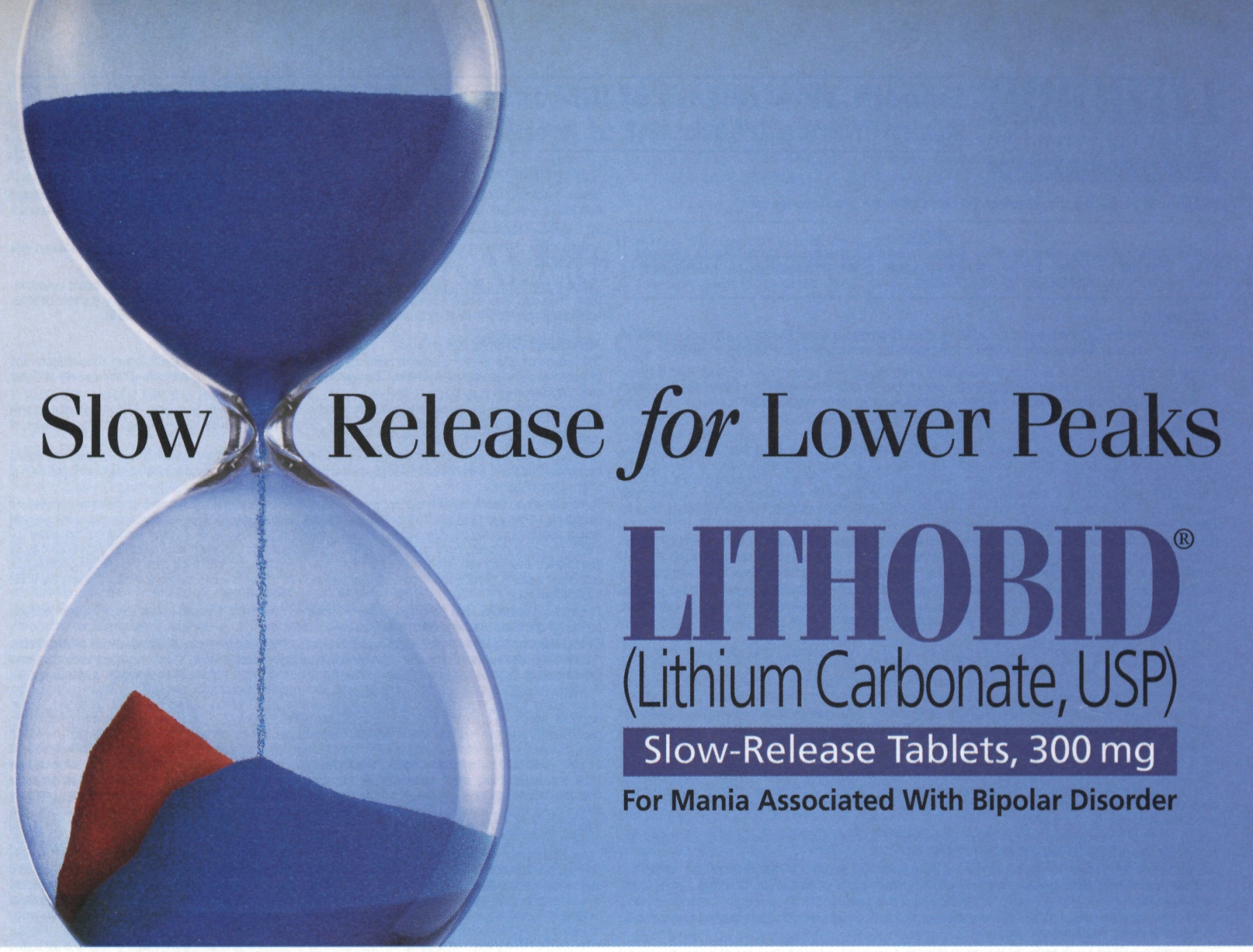

Smoother blood levels than immediate-release litbium may reduce side effects that deter compliance ${ }^{1}$

- Sustained-release formulation helps minimize peak-to-trough variations in serum lithium concentrations'

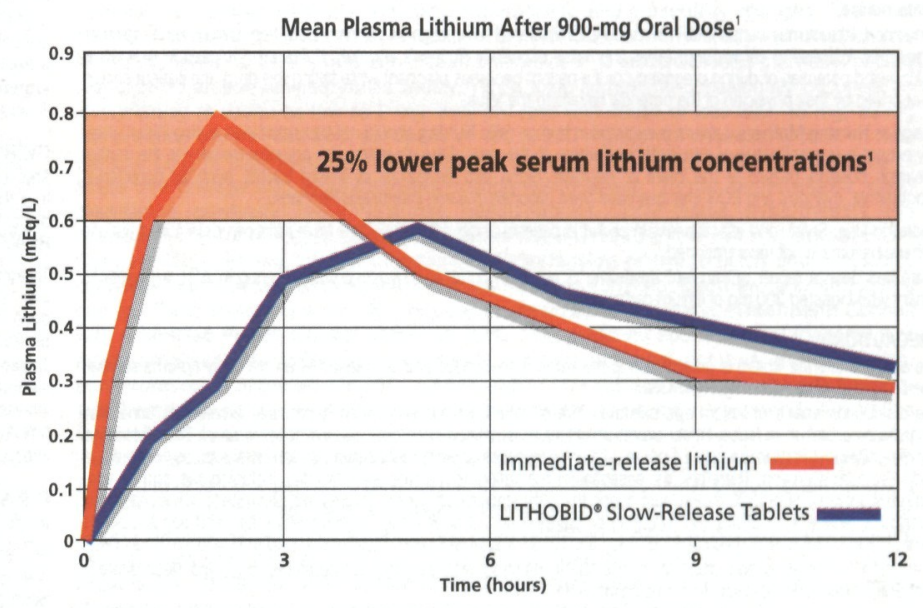

Comparable bioavailability to immediate-release lithium $^{1}$ Small tablet size for easy swallowing (-) Actual size

Common side effects of LITHOBID ${ }^{\oplus}$ Slow-Release Tablets during initial therapy include fine hand tremor, polyuria, mild thirst, and transient and mild nausea. These side effects usually subside with continued treatment, temporary reduction of dosage, or cessation of therapy.

Warning: Lithium toxicity is closely related to serum lithium levels, and can occur at doses close to therapeutic levels. Facilities for prompt and accurate serum lithium determinations should be available before initiating therapy.

Treatment must be individualized according to serum concentrations and clinical response. 


\section{Table of Contents}

Feature Articles

\begin{tabular}{c}
\hline CNS SPECTRUMS \\
\hline The International \\
Journal of \\
Neuropsychiatric \\
Medicine \\
Volume $5 \cdot$ Number 5 \\
May 2000 \\
\hline
\end{tabular}

23 Introduction-An Update on the Neuropsychiatric Aspects of HIV-1 Infection

By Karl Goodkin, MD, PhD, FAPA

25 Theory-Driven Interventions in Psychoneuroimmunology and HIV-1 Infection

By Mary D. Tyll, PhD, Karl Goodkin, MD, PhD, FAPA, Nancy T. Blaney, PhD, Teri T. Baldewicz, PhD, Jodi Dee Hunt, and Deshratn Asthana, PhD

33 Cognitive Effects of HIV-1 Infection

By Frances L. Wilkie, PhD, Karl Goodkin, MD, PhD, FAPA, M. H. van Zuilen, Mary D. Tyll, PhD, Robert Lecusay, and Tony Edwin, MD

55 HIV-1 Infection, Neuroendocrine Abnormalties, and Clinical Outcomes

By Mahendra Kumar, PhD, Karl Goodkin, MD, PhD, FAPA, Adarsh M. Kumar, PHD, Teri T. Baldewicz, PhD,

Robert Morgan, PhD, and Carl Eisdorfer, PhD

66 HIV-1-Associated Neuropathies

By Ashok Verma, MD, DM, and Walter G. Bradley, DM, FRCP

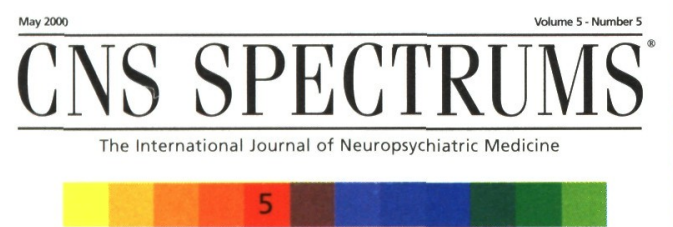

HIV and the

Central Nervous System

Part Two

Theory-Driven Interventions in Psychoneuroimmunology

and HIV-1 Infection

K. Goodkin, N. T. Blaney, T. T. Baldewic

J. D. Hunt, and D. Astbana

Cognitive Effects of HIV-1 Infection

F. L. Wilkie, K. Goodkin, M. H. van Zuilen, M. D. Tyll, R. Lecusay, and T. Edwin

HIV-1 Infection, Neuroendocrine Abnormalties, and Clinical Outcomes

M. Kumar, K. Goodkin, A. M. Kumar, T. T. Baldewicz,

R. Morgan, and C. Eisdorfer

HIV-1-Associated Neuropathies

A. Verma and W. G. Bradley

CNS Spectrums is a peer review journal and is indexed in EMBASE/Excerpta Medica, DIALOG, SilverPlatter, OVID, and Lexis-Nexis. CNS Spectrums is endorsed by, and is the official journal of, the International Neuropsychiatric Association, with members in 30 countries.

\section{CNS Spectrums} (ISSN 1092-8529)

is published monthly by MBL Communications, 665 Broadway, Suite 805 , New York, NY 10012-2302.

Periodicals postage paid at New York, NY, and at additional mailing offices.

One year subscription rates: domestic \$90. foreign $\$ 145$; in-training $\$ 50$.

For subscriptions:

Fax: 212-328-0600.

E-mail:

jpl@medworksmedia.com

Postmaster:

Send address changes to CNS Spectrums

c/o PPS Medical Marketing Group 264 Passaic Ave.

Fairview, NJ 07004-2595 


\section{$\overline{\text { CNS SPECTRLMS }}$}

The International Journal of

Neuropsychiatric Medicine

Volume $5 \cdot$ Number 5 May 2000

\section{Table of Contents}

Departments/MonthIy Columns

POINT \& COMMENTARY

9 HIV and the Brain: Part Two

By Eric Hollander, MD

\section{FIRST PERSON}

19 New Vistas in Drug Abuse Research

By Alan I. Leshner, PhD

\section{CNS NEWS}

24 Briefs from the Fields of Neurology \& Neuropsychiatry

\section{TEACHING MONOGRAPH}

35 Current Treatments of Attention-Deficit/Hyperactivity Disorder By Steven Pliszka, MD, William W. Dodson, MD, and Thomas J. Spencer, MD

\section{CONTINUING MEDICAL EDUCATION}

75 This continuing medical education series gives the reader the opportunity to test his/her understanding and recall of clinical material presented in this issue. Approved for 3.0 credit hours in Category 1.

\section{INDICES}

78 By subject and author

For editorial and advertising inquiries, please fax 212-328-0600.

Opinions and views expressed by authors are their own and do not necessarily reflect the views of the publisher, MBL Communications, or the editorial advisory board. Advertisements in CNS Spectrums are accepted on the basis of adherence to ethical medical standards, but acceptance does not imply endorsement by CNS Spectrums, or the publisher.

CNS Spectrums $\circledast$ is a registered trademark of CNS Spectrums, LLC, New York, NY. CNS News ${ }^{\text {TM }}$ is a trademark of MBL Communications, Inc., New York, NY. 


\section{Now, a little RISPERDAL.}

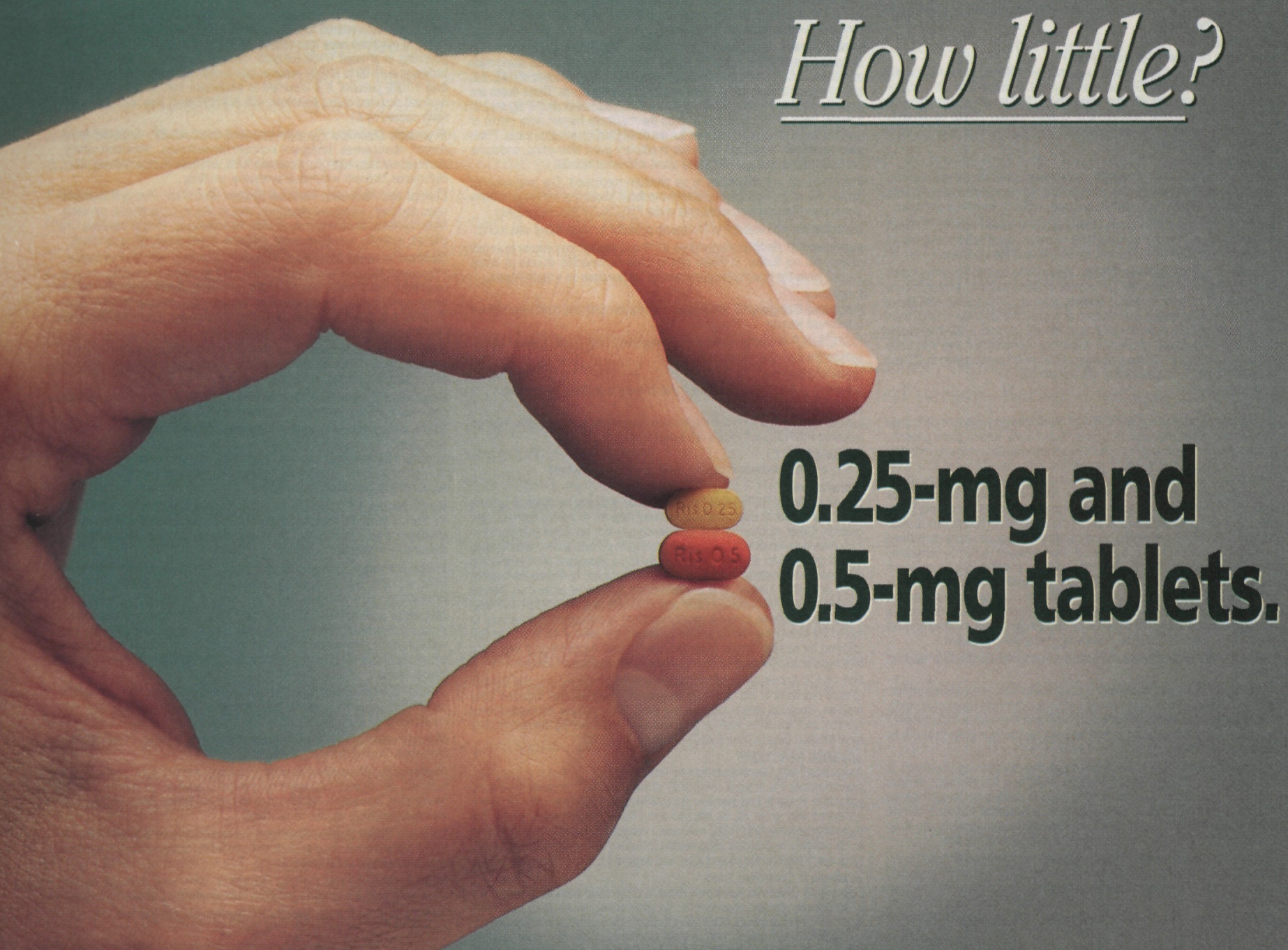

Flexibility of tablets: also $1 \mathrm{mg}, 2 \mathrm{mg}, 3 \mathrm{mg}, 4 \mathrm{mg}$

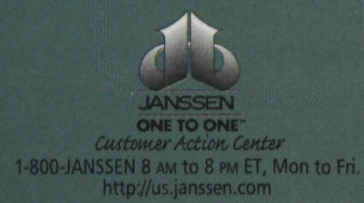

hitp//lus.janssen.com

JANSSEN 圈

Please see brief summary of Prescribing Information on adjacent page.

c) Janssen Pharmaceutica Products, L.P. 2000 and oral solution (1 $\mathrm{mg} / \mathrm{mL}$ ): in $30-\mathrm{mL}$ bottles

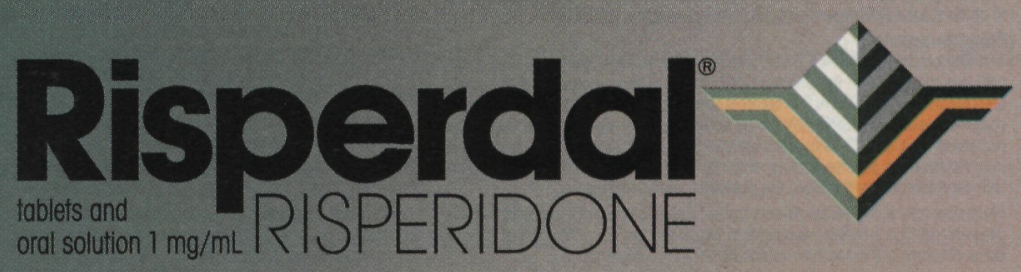




\section{Risperdal}

\section{BEFORE PRESCRIBING, PLEASE CONSULT COMPLETE PRESCRIBING} INFORMATION OF WHICH

RISPERDAI (risperidone) is indicated tor the management of the manifestations of psychotic disorders

CONTRAINDICATIONS

AISPERDAL ${ }^{\circ}$ (risperidone) is contraindicated in patients with a known hyper-

WARNINGS

Neuroleptic Malignant Syndrome (NMS)

A potentially fatal symptom complex sometimes referred to as Neuroleptic Malignant Syndrome (NMS) has been reported in association with antipsy
chotic drugs. If a patient requires antipsychotic drug treatment after recover from NMS the potential reintroduction of drug therapy should be carefully considered. The patient should be carefully monitored, since recurrences of Then reported.

Tardive Dyskinesia

A syndrome of potentially irreversible, involuntary, dyskinetic movements ma develop in patients treated with antipsychotic drugs. Whether antipsychotic If signs and symptoms of tardive dyskinesia appear in a patient on RISPERDAL. drug discontinuation should be considered. However, some patients may requit
treatment with RISPERRDAL ${ }^{\oplus}$ despite the presence of the syndrome.

Potential for Proarrhythmic Effects: Risperidone and/or 9-hydroxyrisperdone appears to lengthen the OT interval in some patients, although there is no average increase in treated patients, even at 12-16 mg/day, well above the recommended dose. Other drugs that prolong the QT interval have been associated with the occurrence of torsades de pointes, a life-threatening arrythmia. Bradycardia, electrolyte imbalance, concomitant use with othe drugs that prolong QT, or the presence of congenital prolongation in QT can increase the risk for occurrence of this arthythmia.

PRECAUTIONS

Genera

Orthostatic Hypotension: RISPERDAL (risperidone) may induce orthostatic

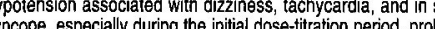
Wncope, especially during the initial dose-titration period, probably reflecting its alpha-adrenergic antagonistic properties. Syncope was reported in $0.2 \%$
(6/2607) of RISPERDAL ${ }^{\circ}$ treated patients in phase 2-3 studies. The risk of orthostatic hypotension and syncope may be minimized by limiting the initia dose to $2 \mathrm{mg}$ total (either QD or $1 \mathrm{mg}$ BID) in normal adults and $0.5 \mathrm{mg} \mathrm{BID} \mathrm{in}$ ADMINISTRATION) Monitoring of orthostatic vital signs should be considere in patients for whom this is of concem. A dose reduction should be considered if hypotension occurs. RISPERDAL ${ }^{\circ}$ should be used with particular caution in patients with known cardiovascular disease (history of myocardial infarction or ischemia, heart failure, or conduction abnormalities), cerebrovascular disease and conditions which would predispose patients to hypotension e.g., dehydration and hypovolemia. Clinically significant hypotension has been observed with concomitant use of RISPERDAL ${ }^{\circ}$ and antihypertensive medication.

Selzures: RISPERDAL" should be used cautiously in patients with a history of

Dysphagia: Esophageal dysmotility and aspiration have been associated with antipsychotic drug use. Aspiration pneumonia is a common cause of morbidity and other antipsychotic drugs should be used cautiously in patients at risk for and other antipsychoic

Hyperprolactinemia: As with other drugs that antagonize dopamine D receptors, risperidone elevates prolactin levels and the elevation persists during chronic administration. Neither clinical studies nor epidemiologic studies conducted to date have shown an association between chronic administration of this class of drugs and tumorigenesis in humans; the
able evidence is considered too limited to be conclusive at this time. Potential for Cognittve and Motor impaiment: Somnolence was a commonly reported adverse event associated with RISPERDAL treatment, especially when ascertained by direct questioning of patients. This adverse event is dos related. Patients should be cautioned about operating hazardous machinery
including automobiles, until they are reasonably certain that PISPERDAL herapy does not affect them adversely.

Priapism: Rare cases of priapism have been reported.

Thrombotic Thrombocytopenic Purpura (TTP): A single case of TTP was reported in a 28 year-old female patient receiving RISPERDAL in a large, open premarketing experience (approximately 1300 patients). She experienced jaundice, fever, and bruising, but eventually recovered after recevi

Antiemetic effect: Rispendone has an antiemetic effect in animals; this effect

Antiemetic effect: Rispendone has an antiemetic effect in animals; this effect
may also occur in humans, and may mask signs and symptoms of overmay also occur in humans, and may mask signs and symptoms of over-
dosage with certain drugs or of conditions such as intestinal obstruction, dosage with certain drugs or of con

Body Temperature Regulation: Disruption of body temperature regulation has been attributed to antipsychotic agents. Caution is advised whe prescribing for patients who will be exposed to temperature extremes. Suicide: The possibility of a suicide attempt is inherent in schizophrenia, and close supervision of high risk patients should accompany drug therapy.

Use in Patients with Concomitant Illness: Clinical experience with limited Caution is advisable in using RISPERDAL ${ }^{\oplus}$ in patients with diseases or conditions that could affect metabolism or hemodynamic responses.

Because of the risks of orthostatic hypotension and QT prolongation, caution should be observed in cardiac patients (See WARNINGS and PRECAUTIONS) Increased plasma concentrations of risperidone and 9-hydroxyrisperidone occur in patients with severe renal impairment and in patients with severe
hepatic impairment. A lower starting dose should be used in such patients. Information for Patients

Physicians are advised to consult full prescribing information to review issues to be discussed with patients for whom they prescribe RISPERDAL ${ }^{\circledR}$

Drug Interactions

The interactions of RISPERDAL ${ }^{\circledR}$ and other drugs have not been systematically evaluated. Given the primary CNS effects of risperidone, caution should drugs and alcohol. RISPERDAL may antagonize the effects of levodopa and dopamine agonists. Chronic administration of carbamazepine with risperidone may increase the clearance of risperidone. Chronic administration of clozapine with risperidone may decrease the clearance of risperidone.

Fluoxetine may increase the plasma concentration of the anti-psychotic fraction done, although not the active metabolite, 9-hydroxyrisperidone.

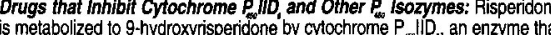
is polymorphic in the population and that can be inhibited by a variety of psychotropic and other drugs (See CLINICAL PHARMACOLOGY). Drug interactions that reduce the metabolism of risperidone to 9-hydroxyrisperidone would increase the plasma concentrations of risperidone and lower the concentrations of 9-hydroxyrisperidone. Analysis of clinical studies involving a modest number of poor metabolizers $(n \approx 70)$ does not suggest that poo and extensive metabolizers have different rates of adverse

In vitro studies showed that drugs metabolized by other $P_{\text {sis }}$ isozymes, including $1 A 1,1 A 2, \| C 9, M P$, and IillA4, are only weak inhibitors of risperidone metabolism Drugs Metabolized by Cytochrome $P_{\text {ec }} \| 1 D_{i}$ : In vitro studies indicate that

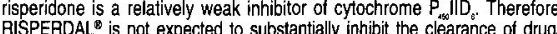
that are metabolized by this enzymatic pathway. However, clinical data to confirm this expectation are not available.

\section{Carcinogenesis, Mutagenesis, Impairment of Fertility}

Carcinogenesis: Carcinogenicity studies were conducted in Swiss albino mice and Wistar rats. Risperidone was administered in the diet at doses of $0.63,2.5$, and $10 \mathrm{mgkg}$ for 18 months to mice and for 25 months to rats. These doses af equivalent to $2.4,9.4$ and 37.5 times the maximum human dose ( $16 \mathrm{mg} / \mathrm{day}$ ) on a mg $\mathrm{kg}$ basis or $0.2,0.75$ and 3 times the maximum human dose (mice) $0.4,1.5$, and 6 times the maximum human dose (rats) on a $\mathrm{mg} / \mathrm{m}^{2}$ basis. There were statistically significant increases in pituitary gland adenomas, endocrin
pancreas adenomas and mammary gland adenocarcinomas.

These findings are considered to be prolactin medicated. The relevance fo human risk of the findings of prolactin-mediated endocrine tumors in rodents
is unknown (See Hyperprolactinemia under PRECAUTIONS, GENERAL).

Mutagenesis: No evidence of mutagenic potential for risperidone was found Impaiment of Fertility: Risperidone ( 0.16 to $5 \mathrm{mg} / \mathrm{kg}$ ) was shown to impa mating, but not fertility, in Wistar rats in three reproductive studies at doses Pregnancy

Pregnancy Category $\mathrm{C}$ : There are no adequate and well-controlled studie RISPERDAL should be used during pregnancy only if the potential benefit ustifies the potential risk to the fetus.

Labor and Delivery

Nursing Mothers

is not known whether or not risperidone is excreted in human milk. Women eceiving RISPERDAL $L^{\oplus}$ should not breast feed.

Pediatric Use

afety and effectiveness in children have not been established.

Geriatric Use

Clinical studies of RISPERDAL did not include sufficient numbers of patients aged 65 and over to determine whether they respond differenty from younger
patients. Other reported clinical experience has not identified differences in patients. Other reported clinical experience has not identified differences in responses between elderty and younger patients. In general, a lower starting dose
is recommended for an elderly patient, reflecting a decreased pharmacokinetic clearance in the elderly, as well as a greater frequency of decreased hepatic, renal, or cardiac function, and of concomitant disease or other drug therapy
(See CLINICAL PHARMACOLOGY and DOSAGE AND ADMINISTRATION) (See CLINICAL PHARMACOLOGY and DOSAGE AND ADMINISTRATION risk in the elderly may be minimized by limiting the initial dose to $0.5 \mathrm{mg}$ BID followed by careful titration (See PRECAUTIONS). Monitoring of orth
vital signs should be considered in patients for whom this is of concem.

This drug is known to be substantially excreted by the kidney, and the risk of toxic reactions to this drug may be greater in patients with impaired ren function. Because elderly patients are more likely to have decreased renal function, care should be taken in dose selection, and it may be
renal function (See DOSAGE AND ADMINISTRATION).

ADVERSE REACTIONS

Associated with Discontinuation of Treatment

Approximately $9 \%$ percent (244/2607) of RISPERDAL (risperidone)-treated patients in phase 2-3 studies discontinued treatment due to an adverse event compared with about $7 \%$ on placebo and $10 \%$ on active control drugs. The ore common events $(\geq 0.3 \%$ ) associated with discontinuation and considered dizziness, typerkinesia, somnolence, and nausea.

ncidence in Controlled Trials

Commonly Observed Adverse Events in Controlled Clinical Trials: In two - to 8-week placebo-controlled trials, spontaneously-reported, treatment the RISPERDAL $L^{\oplus}$ groups and at least twice that of place in at least one of somnolence, extrapyramidal symptoms, dizziness, constipation, nausea, dyspepsia, rinititis, rash, and tachycardia.

Adverse events were also elicited in one of these two trials (i.e., in the fixedcose trial comparing RISPERDAL at doses of 2,6, 10, and $16 \mathrm{mg}$ day with more sensitive than spontaneous reporting. By this method, the following addition $\mathrm{com}$ and and twice the rate of placebo: increased dream activity, increased duration of sleep. accommodation disturbances, reduced salivation, micturition disturbances, diarmea, weight gain, menorhagia, diminished sexual desire, erectile bances, diarmea, weight gain, menorrhagla, diminished sexual
dysfunction, ejaculatory dysfunction, and orgastic dysfunction.

The following adverse events occurred at an incidence of $1 \%$ or more, and were at least as frequent among RISPERDAL ${ }^{\mathbb{B}}$ treated patients treated doses of $\leq 10 \mathrm{mg} / \mathrm{day}$ than among placebo-treated patients in the pooled results of two 6- to 8-week controlled thals: Psychiatric Disorders: insomnla, agitation, anxiety, somnolence, aggressive reaction. Nervous System constipation, nausea, dyspepsia vomiting, abdominal pain, saliva increased, constipation, nausea, dyspepsia, vomiting, abdominal pain, saliva increased,
toothache. Respiratory System: rhinitis, coughing, sinusitis, pharyngitis, dyspnea. Body as a Whole: back pain, chest pain, fever. Dermatological: rash, dy skin, seborrhea. Infections: upper respiratory. Visual: abnormal rash, dry skin, seborrhea. Infections: upper respiratory. Visual:
vision. Musculo-Skeletal: arthralgia. Cardiovascular: tachycardia.

Includes tremor, dystonia, hypokinesia, hypertonia, hyperkinesia, oculogyric
crisis, ataxia, abnormal gait, involuntary muscle contractions, hyporeflexia, crisis, ataxia, abnormal gait, involuntary
akathisia, and extrapyramidal disorders.

\section{Dose Dependency of Adverse Events:}

Data from two fixed dose trials provided evidence of dose-relatedness to extrapyramidal symptoms associated with risperidone treatment. These symptoms include: sleepiness, increased duration of sleep, accommodation disturbances, orthostatic dizziness, palpitations, weight gain, erectile dystunction,
ejaculatory dysfunction, orgastic dysfunction, asthenia/lassitude/increased ejaculatory dystunction, orgastic dystunction
fatiguability, and increased pigmentation.

Vital Sign Changes: RISPERDAL is associated with orthostatic hypotension and tachycardia (See PRECAUTONS)

Weight Changes: A statistically significantly greater incidence of weight gain Laboratory Changes: A between group comparison for 6 - to 8 -week placebodifferences in the proportions of patients experiencing potentially importan changes in routine serum chemistry, hematology, or urinalysis parameters. discontinuations tor changes in serum chemistry, hematology, or urinalysis. However, RISPERDAL administration was associated with increases in serum prolactin (See PRECAUTIONS)

ECG Changes: The electrocardiograms of approximately 380 patients who blind, placebo-controlled trials were evaluated and revealed one finding of blind, placebo-controlled trials were evaluated and revealed one finding of
potential concern; i.e., 8 patients taking RISPERDAL ${ }^{\circ}$ whose baseline QTC interval was less than $450 \mathrm{msec}$ were observed to have QTc intervals greater than 450 msec during treatment (See WARNINGS). Changes of this type were not seen among about 120 placebo patients, but were seen in patients cceiving haloperidol (3/126).

Other Events Observed During the Pre-Marketing Evaluation of RISPERDAL

During its premarketing assessment, multiple doses of RISPERDAL (risperidone) were administered to 2607 patients in phase 2 and 3 studies and the tollowing reactions were reported: (Note: frequent adverse events are those ccurring in 1/100 to $1 / 1000$ patients; rare events are those occurring in fewer than $1 / 1000$ patients. It is important to emphasize that, although the events sarily caused by it.)

Psychiatric Disorders: Frequenti increased dream activity ${ }^{*}$ diminished sexual desire*, nervousness. Infrequent: impaired concentration, depression, apathy, catatonic reaction, euphoria, increased libido, amnesia.
nightmares, delirium, withdrawal syndrome, yawning.

Central and Peripheral Nervous System Disorders: Frequent: increased sleep duration". Infrequent: dysarthria, vertigo, stupor, paraesthesia, contusion. Rare: aphasia, cholinergic syndrome, hypoesthesia, tongue paralysis, leg cramps, torticollis, hypotonia, coma, migraine, hyperreflexia, choreoathetosis. Gastro-intestinal Disorders: Frequent: anorexia, reduced salivation * Infrequent: flatulence, diarrhea, increased appetite, stomatitis, melena,
dysphagia, hernorthoids, gastritis. Rare: tecal incontinence, enctation, gastroesophageal reflux, gastroenteritis, esophagitis, tongue discoloration, cholelithiasis, tongue edema, Body as a Whole/General Disorders: Frequent: fatigue. Inirequent: edema,
rigors, malaise, influenza-fike symptoms. Rare: pallor, enlarged abdomen, rigors, makaise, influenza-like symptoms. Ra
allergic reaction, ascites, sarcoidosis, flushing.

Respiratory System Disorders: Infrequent: hyperventilation, bronchospasm, pneumonia, stridor. Rare: asthma, increased sputum, aspiration.

Skin and Appendage Disorders: Frequent: increased pigmentation ${ }^{*}$, photosensitivity*. Infrequent: increased sweating, acne, decreased sweating, alopecia, hyperkeratosis, pruritus, skin exfoliation. Rare: bullous eruption, skin
ulceration, aggravated psoriasis, furunculosis, verruca, dermatitis lichenoid, ulceration, aggravated psoriasis, furunc
hypertrichosis, genital pruritus, urticania.

Cardiovascular Disorders: Infrequent: palpitation, hyportension, hypotension, AV block, myocardial infarction. Rare: ventricular tachycardia, angina pectoris, premature atrial contracition

Vision Disorders: Infrequent: abnormal accommodation, xerophthalmia. Rare: diplopia, eye pain, blepharitis, photopsia, photophobia, abnormal Rerimation.

Metabolic and Nutritional Disorders: Infrequent: hyponatremia, weight ncrease, creatine phosphokinase increase, thirst, weight decrease, diabetes mellitus. Rare: decreased serum iron, cachexia, dehydration, hypokalemia, hypoproteinem

Urinary System Disorders: Frequent: polyuria/polydipsia*. Infrequent: urinary incontinence, hematuria, dysuria. Rare: urinary retention, cystitis, renal insufficiency.

Musculo-skeletal System Disorders: Infrequent; myalgia. Rare: arthrosis, synostosis, bursitis, arthritis, skeletal pain.

Reproductive Disorders, Female: Frequent: menorrhagia*, orgastic dysfunction*, dry vagina*. Infrequent: nonpuerperal lactation, amenormea, female breast pain, leukorthea, mastitis, dysmenorthea, female perineal pain, intermenstrual bleeding, vaginal hemorihage.

Liver and Biliary System Disorders: Infrequent: increased SGOT, increased SGPT. Rare: hepatic failure, cholestatic hepatitis, cholecystitis, cholelithiasis,
hepatitis, hepatocellular damage.

Platelet, Bleeding and Clotting Disorders: Infrequent: epistaxis, purpure Rare: hemornhage, superficial phlebitis, thrombophlebitis, thrombocytopenia. Hearing and Vestibular Disorders: Rare: tinnitus, hyperacusis, decreased hearing.

Red Blood Cell Disorders: Infrequent: anemia, hypochromic anemia. Rare: normocytic anemia.

Reproductive D

White Cell and Resistance Disorders: Rare: leukocytosis, lymphadenopathy, eucopenia, Pelger-Huet anomaly.

Endocrine Disorders: Rare: gynecomastia, male breast pain, antidiuretic homone disorder.

Special Senses: Rare: bitter taste.

Incidence based on elicited reports.

Postintroduction Reports: Adverse events reported since market introduction which were temporally (but not necessarily causally) related to RISPERDAL ${ }^{\infty}$ therapy, include the following: anaphylactic reaction, angioedema, apnea, atrial fibrillation, cerebrovascular disorder, diabetes mellitus mania, pancreatitis, Parkinson's disease aggravated, pulmonary embolism There have been rare reports of sudden death and/or cardiopulmonary arrest in patients receiving RISPERDAL ${ }^{\circ}$. A causal relationship with RISPERDAL ${ }^{\infty}$ has not been established. It is important to note that sudden and unexpected death may occur in psychotic patients whether they remain untreated or whether they are treated with other antipsychotic drugs.

DRUG ABUSE AND DEPENDENCE

Controlled Substance Class: RISPERDAL (risperidone) is not a controlled substance.

For information on symptoms and treatment of overdosage, see full prescribing information.

More detailed professional infomation is available upon request.

- Janssen Pharmaceutica Inc. 1999

S Patent 4,804,663

7503217

JANSSEN 年 iresearchaceutica.

Titusville, NJ 08560 